\title{
Burocracia, discricionariedade e democracia: alternativas para o dilema entre controle do poder administrativo e capacidade de implementação
}

\author{
Roberto Rocha Coelho Pires ${ }^{1}$
}

RESUMO: Sob que condições é possível conciliar o aumento do controle sobre a atuação do Estado e a expansão da capacidade de ação de suas burocracias? A partir de uma retrospectiva histórica das abordagens sobre esse tema, o presente estudo se dedica a avaliar os efeitos de diferentes modelos de gestão (abordagens gerencialista e experimentalista) e suas respectivas estratégias para o gerenciamento da discricionariedade burocrática sobre o desempenho de burocracias na implementação de políticas públicas. Lançando mão de um desenho de pesquisa "quase experimental”, que possibilita uma série de comparações controladas entre tais modelos de gestão, o presente estudo indica que os instrumentos e estruturas de controle interno sugeridos por cada abordagem possuem impactos importantes e diferenciados nos níveis de motivação, criatividade na solução de problemas locais e responsividade de burocratas.

PALAVRAS-CHAVE: Burocracia, discricionariedade, accountability, implementação de políticas públicas, aprendizado organizacional.

ABSTRACT: Under what conditions can we reconcile heightened accountability with increased state capacity? The study draws from a brief historical retrospective of the dilemma control-capacity and of responses to the problem of discretion in public administration. It then focuses on the effects of different public sector management models (i.e. new public management vs. experimentalist governance approaches, and their respective strategies for managing bureaucratic discretion) on the performance of bureaucracies in the implementation of public policies. The study deploys a quasi-experimental research design, which allows for a series of controlled comparisons between management models. The findings indicate that the different accountability tools and structures offered by each model exhibit different and important impacts on the levels of staff motivation, creativity in the solution of local problems, and bureaucratic responsiveness.

KEYWORDS: Bureaucracy, discretion, accountability, policy implementation, organizational learning.

\footnotetext{
${ }^{1}$ Doutor em Políticas Públicas pelo Massachusetts Institute of Technology. Mestre em Ciência Política pela Universidade Federal de Minas Gerais. Bacharel em Administração Pública pela Fundação João Pinheiro. Técnico de Pesquisa e Planejamento no Instituto de Pesquisa Econômica Aplicada. E-mail: roberto.pires@ipea.gov.br
} 
"Managing discretion is at the heart of the problem of street-level bureaucracy”

(Lipsky, 1980, p. 196)

"If you ride a horse, sit close and tight. If you ride a man, sit easy and light”

(Poor Richard’s Almanack, 1734)

\section{Introdução}

Um dos desafios centrais para as democracias contemporâneas é equacionar o dilema entre o controle da atuação do Estado e a expansão da capacidade de ação e resolução de problemas por parte de suas burocracias. Se, por um lado, a imposição de controles sobre o poder administrativo de agentes burocráticos, encarregados de implementar políticas públicas e decisões políticas, favorece o exercício de mandatos representativos e a integridade do sistema de checks and balances, por outro, o excesso de controles limita a criatividade e a capacidade de ação desses agentes na consecução de objetivos importantes para o bem-estar da sociedade. Este estudo parte do reconhecimento de que o poder discricionário de burocratas nas linhas de frente do serviço público está no centro do dilema entre controle e expansão da capacidade de ação do Estado. Isto é, a discricionariedade é foco das investidas de controle assim como fonte de flexibilidade e criatividade para ação burocrática. Portanto, uma análise cuidadosa das alternativas existentes para o gerenciamento da discricionariedade burocrática é passo fundamental na compreensão das condições e estruturas que possibilitem a reconciliação entre controle e capacidade na burocracia.

Nas próximas páginas, primeiramente traça-se uma breve revisão do tratamento dado à questão da discricionariedade burocrática nos debates da sociologia do direito e da ciência política desde meados do século XX. Na sequência, abordam-se dois modelos contemporâneos de administração pública - as abordagens gerencialista (New Public Management) e experimentalista (Experimentalist Governance) - com a descrição de suas principais diferenças em relação às respostas tradicionais envolvendo direito administrativo 
e controles internos e externos ao problema da discricionariedade burocrática. Por meio da comparação entre esses dois modelos, é possível identificar variações importantes em termos de estratégias para compatibilização da ampliação do desempenho organizacional com mecanismos de controle sobre o mau uso da discricionariedade. Após a descrição dos modelos, desenvolve-se um quase experimento ${ }^{2}$ que permite a comparação empírica desses dois modelos sob o mesmo ambiente organizacional. Com base em dados coletados por meio de pesquisa de campo - conduzida entre dezembro/2006 e agosto/2008 na Secretaria de Inspeção do Trabalho, no Ministério do Trabalho e Emprego, assim como em suas Superintendências Regionais - o estudo demonstra como cada modelo conforma diferentemente rotinas de trabalho de inspeção, consequentemente influenciando os resultados da política de inspeção do trabalho no Brasil. Finalmente, apontam-se os aspectos mais salientes dessa comparação e propõem-se de forma conclusiva hipóteses mais gerais sobre a relação entre formas de accountability e motivação de funcionários, e entre formas colaborativas de trabalho, capacidade para solução de problemas e responsividade burocrática.

\section{O Temor da discricionariedade e respostas contemporâneas na administração pública}

O tema da discricionariedade de agentes burocráticos nas linhas de frente do serviço público foi tradicionalmente tratado como uma categoria residual por estudiosos da administração do Estado (DAVIS, 1969; HAWKINS, 1992). ${ }^{3}$ Isso se deve, em parte, à ampla aceitação de interpretações relativamente superficiais dos escritos de Max Weber sobre burocracia. Para Weber, burocracia representava a forma organizacional de um

\footnotetext{
${ }^{2}$ Um quase experimento envolve a ocorrência natural ou espontânea de fenômenos observáveis, aproximando-se e partilhando propriedades importantes de um experimento científico controlado, com a única exceção da seleção aleatória de grupos/amostras (assunto a ser discutido em maior detalhe na seção sobre desenho e estratégias metodológicas). Um desenho de pesquisa quase experimental permite a comparação de diferentes grupos (ex.: modelos de gestão diferentes) e de seus potenciais efeitos sobre os resultados (ex.: o desempenho de burocratas), minimizando problemas de validade externa. Uma vez que quase experimentos são experimentos que ocorrem naturalmente - isto é, não intencionalmente provocados pelo pesquisador - as conclusões resultantes de uma análise podem ser aplicadas a outros objetos e situações semelhantes, permitindo algumas generalizações sobre as características e comportamento da população. Quase experimentos constituem tentativas de exploração de relações causais (baseadas nas diferenças e semelhanças entre grupos examinados), mesmo que o pesquisador não tenha controle sobre todos os fatores que afetam os resultados observados (MCDERMOTT, 2002; GIBSON et al, 2002; GRIBBONS e HERMAN, 1997).

${ }^{3}$ De acordo com Davis (1969), antes dos anos 1970, havia numerosos estudos que abordavam ainda que de forma tangente o tema da discricionariedade. Porém poucos focaram o tema como objeto central de análise. Tal como afirma o autor, tradicionalmente, estudos de jurisprudência focavam muito mais a legislação; estudos na administração pública negavam o componente humano-individual e orientado por valores na gestão de organizações; e estudos na área de direito administrativo acabavam restringindo-se ao pequeno percentual de ações que envolviam procedimentos formais e recurso judicial.
} 
sistema sociopolítico (sistema de dominação) que se diferenciava de outros tipos-ideias de organização, como as formas de dominação carismática e patriárquica. Nas últimas duas formas de dominação, o exercício do poder legitima-se, respectivamente, pelas características extraordinárias do líder ou pela tradição. Em oposição a essas formas de dominação historicamente mais preponderantes, Weber descreveu burocracias e a forma racional-legal de dominação como o poder baseado nas regras, nas quais procedimentos formais: estabelecem uma linha de comando clara por meio de estruturas hierárquicas; prescrevem os pré-requisitos, deveres e competências atribuídos a cada cargo nessas estruturas; promovem a divisão do trabalho (especialização); definem os procedimentos e escopo dos processos de tomada de decisão em todos os níveis da organização (incluindo as decisões sobre mudança nas regras); e especificam os processos para sucessão no poder. Essas características da organização racional-legal cumulativamente levam ao controle de inclinações pessoais e desejos e opiniões individuais, minimizando a influências destes no funcionamento da organização (WEBER, 1968).

É importante reconhecer que Weber não partiu do princípio de que regras são mecanismos de controle originalmente perfeitos que podem prever e organizar toda e qualquer situação e comportamento individual. Para Weber, a forma de dominação burocrática não envolve apenas a formalização e predefinição das formas permitidas de relação social, mas fundamentalmente um processo gradual e incessante de racionalização da administração (meios e fins) e do direito. Portanto, lacunas nos procedimentos formais - isto é, situações e comportamentos não previamente descritos ou ditados por regras formais - gradual e inevitavelmente acabariam por serem submetidas a regras organizacionais como o resultado de uma tendência inexorável em direção à burocratização e à racionalização formal de todas as esferas da vida social (MOMMSEN, 1989).

A conceitualização (tipo-ideal) de burocracia desenvolvida por Weber vislumbrava um arcabouço institucional abrangente, transformando agentes burocráticos em engrenagens impessoais numa máquina organizacional pré-programada. Essa forma de descrever a burocracia proveu o arcabouço teórico-conceitual que se tornou hegemônico ${ }^{4}$ e levou a

\footnotetext{
${ }^{4}$ É importante notar que uma série de estudos na sociologia das organizações, como, por exemplo, Gouldner (1954) e Crozier (1964), já contestaram e sugeriram revisões na concepção weberiana de burocracia.
} 
interpretação de burocracias reais (e não só como tipos-ideiais) como possuidora do “domínio das regras formais ao invés da discricionariedade pessoal no seu cerne” (LANGE e RUESCHMEYER, 2005, p. 241). Com base nessa interpretação, muitos estudiosos das implicações teóricas e empíricas da expansão de burocracias enfatizaram a impessoalidade, o comportamento ditado por regras, a previsibilidade e coerência corporativa como as características essenciais do Estado moderno, as quais transformariam este em catalisador do desenvolvimento socioeconômico (JOHNSON, 1982; AMSDEN, 1992; EVANS, 1989; 1995; WADE, 1990; EVANS e RAUCH, 1999; LANGE e RUESCHEMEYER, 2005; DONER, RITCHIE e SLATER, 2005).

No entanto, há décadas, estudos empíricos na sociologia do direito e na implementação de políticas públicas concluíram sobre a inevitabilidade e o caráter indispensável da discricionariedade para o funcionamento de sistemas legais e administrativos. De um lado, as investigações de Wilson (1968), Bittner (1967; 1990), Brown (1981), Van Maanen (1973; 1978) e Silbey (1980-81), entre outros, sobre o trabalho de organizações policiais e outros agentes da lei concluíram que: a) frequentemente, as atividades corriqueiras desses burocratas divergiam substancialmente dos conjuntos de condutas prescritos pela lei e por estatutos e normas organizacionais; e b) o comportamento dessas burocracias variava significativamente entre si, assim como variava o comportamento de agentes e unidades no interior das mesmas organizações. ${ }^{5}$ Essas conclusões frustraram as expectativas de que mandatos legais traduzir-se-iam automaticamente em ações burocráticas e levaram estudiosos do tema a reconhecer a abrangência e inevitabilidade da discricionariedade em burocracias (DAVIS, 1969; SILBEY e BITTNER, 1982; HAWKINS, 1992).

Paralelamente, achados semelhantes emergiram no campo de estudos sobre políticas públicas à medida que pesquisadores tentavam explicar a dissonância entre os objetivos almejados por políticas públicas e os objetivos efetivamente alcançados. Algumas das primeiras tentativas enfatizaram a complexa rede de obstáculos e dificuldades na

\footnotetext{
${ }^{5}$ Um exemplo clássico dos estudos pioneiros a documentar variações no estilo de implementação por parte de agentes da lei, Wilson (1968) observou o comportamento de policiais durante seu trabalho corriqueiro em oito comunidades distintas nos Estados Unidos e descobriu uma variação substantiva na forma como tais policiais faziam seu trabalho. Em alguns departamentos de polícia, os policiais eram mais tolerantes com violações menores da lei e enfatizavam a orientação e a manutenção da ordem; em outros departamentos, os policiais exerciam seu poder de coerção para toda e qualquer violação da lei.
} 
implementação de políticas públicas (PRESSMAN e WILDAVSKY, 1973; BARDACH, 1977). Porém, alguns anos depois, pesquisas sobre os funcionários nas linhas de frente da implementação de políticas, os chamados street-level bureaucrats (LIPSKY, 1980), ${ }^{6}$ demonstraram como as decisões individuais tomadas por esses funcionários no ato da implementação, em respostas a incertezas e pressões vividas por eles, se tornam efetivamente a política pública que eles executam em nome de sua organização (LEONARD, 1977; LIPSKY, 1980; WILSON, 1989; MAYNARD-MOODY e MUSHENO, 2003).

Apesar de as conclusões desses estudos apontarem para uma suposta inevitabilidade da discricionariedade, os debates na ciência política e administração pública se caracterizaram mais pelo medo da tirania e abuso do poder por parte de burocracias e pelos riscos associados com a tomada de decisões não supervisionadas (unchecked), do que pelos potenciais benefícios do exercício responsável da discricionariedade. Na tradição liberallegalista, a discricionariedade foi repetidamente interpretada como uma ameaça ao estado de direito ou uma fissura no contrato social, criando espaço para inconsistência administrativa, arbitrariedade e, consequentemente, injustiça. Essa tradição de pensamento político prega que a discricionariedade burocrática deve ser confinada, estruturada e limitada pelo direito administrativo - os procedimentos e regras que ditam a conduta e práticas de agentes administrativos (DAVIS, 1969; HANDLER, 1986; BRYNER, 1987; HAWKINS, 1992).

Por sua vez, para os cientistas políticos mais atentos à estrutura institucional da democracia do que ao processo legal, a discricionariedade também sugere ameaças à noção de responsabilização política (ou accountability entre burocratas, representantes eleitos e cidadãos), além de por em questão o equilíbrio da estrutura constitucional de separação de poderes e os mecanismos de checks and balances. Na tradição da democracia constitucional, muita atenção tem sido devotada à limitação da discricionariedade

\footnotetext{
${ }^{6}$ Para Lipsky (1980), street-level bureaucracies são organizações do serviço público que empregam um número significativo de funcionários que interagem diretamente com cidadãos no desempenho de suas funções - tais como professores, enfermeiros, policiais, assistentes sociais e outros agentes da lei. Esses funcionários têm ampla discricionariedade devido às ambiguidades nos objetivos de suas organizações, ao fato de trabalharem em situações complicadas que não podem ser reduzidas a formatos programáticos e ao fato de que desempenham suas tarefas longe da supervisão de seus superiores. Por todas essas razões, Lipsky afirma que "as decisões tomadas por street-level bureaucrats, as rotinas estabelecidas por eles e os recursos por eles desenvolvidos para lidar com as incertezas e pressões do trabalho efetivamente se tornam a política pública que eles deveriam implementar em nome de sua organização” (1980).
} 
burocrática por meio da instituição de mecanismos de supervisão e controle do desempenho de burocracias por parte do Legislativo (controle externo, como o Tribunal de Contas da União), do Gabinete do Presidente (controle interno, como a Controladoria Geral da União) e da sociedade civil (instituições participativas como conselhos, audiências públicas etc.) (CALVERT et al, 1989; MCCUBBINS et al, 1987; MCCUBBINS e SCHWARTZ, 1984).

Avaliações retrospectivas demonstraram que procedimentos legais e o controle e supervisão de burocracias de fato reduzem os níveis de discricionariedade. Porém, também indicaram que o remédio pode ter sido tão ruim, senão pior, do que a própria doença. Por exemplo, Bryner (1987) e Handler (1986) documentaram como ações excessivas no sentido da redução da discricionariedade comprometeram a capacidade de organizações do setor público de desempenhar tarefas a ela delegadas, uma vez que processos administrativos se tornam mais complexos e lentos, impossibilitando que organizações funcionem efetivamente. Consequentemente, uma ênfase excessiva nos procedimentos burocráticos de controle minou esforços paralelos no sentido de ajudar organizações burocráticas a tomarem decisões complexas necessárias à implementação de políticas públicas.

Nas últimas décadas, à medida que os esforços para limitar a discricionariedade burocrática a custa de capacidade organizacional provaram ser pouco eficazes, duas outras abordagens na literatura sobre administração pública proveram modelos que pretendem equilibrar o controle das decisões discricionárias de burocratas com a busca pela ampliação de capacidade e competências em burocracias. Contrariamente aos esforços anteriores, esses novos modelos de administração pública enfatizam estruturas organizacionais e práticas gerenciais, ao invés de regras e procedimentos (i.e. direito administrativo e supervisão externa), como meios mais pragmáticos e efetivos para o gerenciamento da discricionariedade. $^{7}$

Primeiramente, o paradigma do New Public Management (NPM) tornou-se um dos mantras da reforma do setor público por todo o mundo nos anos 1980 e 1990. No contexto da falência do Estado, da precária atuação de burocracias nas décadas anteriores e do

\footnotetext{
${ }^{7}$ Outra corrente da literatura sobre controles da discricionariedade burocrática, caracterizada por uma perspectiva sociológica, enfatiza ainda formas para o gerenciamento da discricionariedade alternativas a regras e estruturas organizacionais, chamando atenção para elementos como: cultura organizacional, contexto, normas sociais, grupos etc. (HAWKINS, 1992; BAUMGARTNER, 1992).
} 
descontentamento generalizado com o desempenho de governos, a abordagem gerencialista trouxe consigo novas esperanças. Com seu foco em resultados e na otimização do orçamento público, essa abordagem promete a melhoria na eficiência e responsividade de burocracias aos seus principals políticos e cidadãos. A vasta literatura sobre o assunto identifica três características principais das reformas do setor público orientadas pelos princípios gerencialistas: a) descentralização, com a desagregação do Estado em atores subnacionais, cisão de grandes estruturas hierárquicas, e separação de funções de governo essenciais (core) daquelas consideradas auxiliares ou complementares; b) privatização e competição, com a desregulamentação de mercados, criação de quase mercados para grande parte dos serviços públicos e parcerias público-privado (PPPs); e c) gestão do desempenho, com a instituição de metas e indicadores de resultados para a mensuração do desempenho de organizações e seus burocratas, além de uma forte ênfase em incentivos específicos com base pecuniária, tais como sistemas de gratificação por desempenho (OSBORNE e GAEBLER, 1992; DUNLEAVY e HOOD, 1994; POLLIT, 1995; BRESSER-PEREIRA e SPINK, 1999; BARZELAY 2001).

A solução gerencialista ao problema da discricionariedade pretendeu evitar os erros do passado ao enfatizar a mensuração dos resultados ao invés do controle de processos, tal como feito por procedimentos legais e administrativos. Sob esse modelo, organizações do setor público devem definir uma lista de metas de desempenho que possam ser definidas de forma específica, quantificável e mensurável. Cada burocrata na organização deve cumprir uma parte do objetivo geral. Supervisores monitoram constantemente o desempenho de seus burocratas em termos da consecução dessas metas, tendo como referências indicadores quantitativos de resultados. De forma a prover os incentivos corretos, gestores administram a distribuição de gratificações nos salários apenas dos funcionários que satisfizerem periodicamente as metas. Assim, a solução gerencialista restringe a discricionariedade burocrática ao fornecer fortes incentivos (aumentos significativos sobre salários) somente para aquelas ações e objetivos desejados por gestores sem reduzir dramaticamente a capacidade de burocratas de implementar políticas públicas - isto é, à medida que propõe também a simplificação e otimização de processos administrativos e não predetermina procedimentos e instrumentos para ação. 
Em segundo lugar, a abordagem experimentalista ou Experimentalist Governance (EG) emergiu como uma crítica por parte de seus proponentes (Sabel, Zeitlin, Dorf, Simon, entre outros) à insustentabilidade empírica do arcabouço econômico-racional que está no cerne da proposta gerencialista, mais precisamente os pressupostos sobre as relações agentprincipal. Com inspiração no institucionalismo econômico, a abordagem gerencialista em geral separa os momentos de concepção/decisão das ações associados com sua execução, pressupondo a existência de principals (sejam eles atores da sociedade civil, partidos políticos, ou representantes eleitos) que saibam tudo o que precisa ser feito para a solução de problemas coletivos. Supostamente, esses principals estão aptos a traduzir objetivos coletivos em metas de desempenho detalhadas - por exemplo, um aumento de 50\% na formalização do trabalho, uma redução de $20 \%$ na evasão escolar etc. Em contraposição, os proponentes da abordagem experimentalista defendem que principals com tal conhecimento robusto e panorâmico não existem nas comunidades políticas reais, muito menos um consenso inquestionável sobre quem deveria desempenhar tal papel diretivo. Portanto, segundo esses autores, o problema da reforma do setor público não se resume apenas à definição de metas de desempenho e do respectivo sistema de incentivos, mas sim envolve a construção de processos por meio dos quais os atores envolvidos interajam, descubram e aprendam conjuntamente aquilo que precisa ser feito e a melhor forma possível de executá-lo (SABEL, 2004; 2005).

Assim, de acordo com esse modelo de gestão, a solução requer instituições experimentalistas "that assume the provisionality of their goals and institutionalize social learning by routinely questioning the suitability of their current ends and means, and by periodically revising their structures in light of the answers” (SABEL, 2004, p. 4). Instituições experimentalistas demonstram a atitude de constante detecção e correção de erros nos níveis operacionais da organização, ajustando, na sequência, as estruturas superiores para a generalização de sucessos e aprimoramento do sistema de aprendizado a partir de erros. Por meio de ajustes reflexivos constantes, os proponentes da abordagem experimentalista argumentam que burocracias públicas podem simultaneamente: a) expandir suas capacidades para solução de problemas complexos por meio da adaptação rápida às condições externas em constante mudança e da possibilidade de customização de suas ações a diversas clientelas; e b) incrementar a prestação de contas por parte de 
burocratas de linha de frente aos seus supervisores e ao público em geral em relação a sua conduta. Tal como exemplificado pela reforma de serviços de assistência à criança e ao adolescente nos Estados Unidos:

"The reforms do not achieve accountability by constraining frontline decisions through rules. Rather, frontline discretion is increased, but joined to the requirement that, in the course of establishing and adjusting plans for children, frontline workers and the professionals and stakeholders with whom they collaborate explain the choices they make in terms of the governing values of the program. Review of these explanations in turn allows administrative superiors and outside oversight bodies to detect and begin considering how to correct misjudgments by individual case workers, systemic flaws in operating routines at the local office or program level, and even ambiguity or mistake in the agency's own conception of its key commitments and plans for achieving them. Thus, the agency learns to improve while monitoring what it does, and the same process that makes customization of services effective makes it accountable as well. We call such learningby-monitoring institutions 'experimentalist'” (NOONAM, SABEL e SIMON, 2007, p. 3).

Recentes avanços por parte de instituições experimentalistas vêm sendo registrados em diferentes países, assim como em diferentes áreas do serviço público. Em todos esses $\operatorname{casos}^{8}{ }^{8}$ analistas atribuíram os resultados exitosos à maior autonomia gozada por burocratas de linha de frente na adaptação dos objetivos de políticas e projetos durante sua implementação em cada situação específica, além do estabelecimento de mecanismos para constante deteç̧ão e correção de erros baseados em relatórios e justificativas por parte de burocratas (comissões de avaliação interna, revisão por pares etc.), os quais culminam na revisão periódica de procedimentos e objetivos organizacionais mais amplos.

\footnotetext{
${ }^{8}$ Essas experiências incluem: a reforma de escolas públicas e esquemas de metarregulação na área de vigilância sanitária nos Estados Unidos (SABEL, 2004), a reforma da assistência à criança e ao adolescente nos estados de Alabama e Utah (NOONAM, SABEL e SIMON, 2007), provisão de assistência e benefícios sociais na Holanda, Dinamarca e Irlanda (SABEL, 2005), sistemas de proteção social, saúde e segurança ocupacional, vigilância sanitária, telecomunicações, eletricidade, segurança marítima e serviços financeiros na União Européia (SABEL e ZEITLIN, 2008).
} 
Esses dois modelos de gestão pública expõem soluções bem diferentes para o problema da discricionariedade burocrática. A solução gerencialista enfatiza o desenvolvimento de projetos cada vez mais focados nos quais burocratas podem ser cobrados pela consecução de metas específicas e quantificáveis. Já a solução experimentalista sugere um processo pelo qual burocratas são constantemente demandados a explicar e justificar suas ações discricionárias na solução de problemas por meio de processos de avaliação pública por seus superiores ou pares.

O debate sobre a eficácia desses dois modelos encontra-se em andamento e o volume de pesquisa acadêmica sobre eles está em crescimento. Entretanto, esforços para comparar esses dois modelos lado a lado, e suas implicações para a governança e gestão de burocracias, permanecem escassos. Este estudo pretende preencher essa lacuna e ampliar nossa compreensão sobre o tema, comparando como esses dois modelos: a) organizam o trabalho e as práticas de burocratas; b) influenciam os resultados da implementação de políticas públicas; e c) assim como suas vantagens e desvantagens como soluções alternativas para o gerenciamento da discricionariedade.

\section{Uma organização e dois modelos de gestão: desenho de pesquisa e métodos}

O presente estudo emprega um desenho de pesquisa quase experimental ${ }^{9}$ ao observar a operação de ambos os modelos - gerencialista e experimentalista - no âmbito da mesma agência governamental, a Secretaria de Inspeção do Trabalho (SIT) do Ministério do Trabalho e Emprego (MTE). A missão da organização é verificar e impor o cumprimento das leis e normas trabalhistas nacionais, o que inclui desde regras sobre contratos e jornadas de trabalho às normas de saúde e segurança ocupacionais. A competência para tal

\footnotetext{
${ }^{9}$ O presente estudo envolve a observação sistemática de fenômenos distintos (modelos de gestão) que ocorrem sob condições aproximadamente estáveis e controladas (ambiente organizacional). Entretanto, mesmo que muitas variáveis relevantes sejam mantidas constantes (como será descrito adiante no corpo texto), o presente desenho de pesquisa não controla a seleção e designação dos indivíduos que participam de cada grupo (atuando sob diferentes modelos de gestão). Diferentemente de um experimento no qual grupos ou casos são designados aleatoriamente por pesquisadores, em um quase experimento os grupos a serem comparados são preexistentes ou ocorrem naturalmente, isto é, sem a intervenção do pesquisador. Diferentemente de um experimento científico clássico, portanto, os grupos de um quase-experimento não são probabilisticamente equivalentes. Ao contrário, supõe-se desde o início que tais grupos serão diferentes entre si em alguma qualidade essencial, como, por exemplo, rotinas de trabalho, procedimentos e estruturas de gestão (GIBSON et al, 2002). Portanto, ao invés de enfatizar as características de indivíduos envolvidos no experimento, o estudo examina em que medida diferentes modelos de gestão têm maior ou menor propensão de influenciar o comportamento de burocratas na execução de suas tarefas organizacionais.
} 
concentra-se no Governo Federal, mas a implementação de tal missão ocorre por meio de um sistema desconcentrado que envolve a distribuição de aproximadamente 3.000 Auditores-Fiscais do Trabalho em 27 Superintendências Regionais de Trabalho em Emprego. Os Auditores-Fiscais do Trabalho (AFTs) têm a responsabilidade de oferecer cobertura a mais de 78 milhões de trabalhadores empregados nos setores formal e informal, em 2,7 milhões de empresas formais e em um sem número de empresas informais, em todos os 5.564 municípios brasileiros. Mesmo não possuindo os recursos humanos e materiais para dar conta de uma tarefa de tal magnitude, a organização e a carreira de fiscal do trabalho têm sido aprimoradas de forma significativa desde a redemocratização do país em 1985. Desde então, a SIT ampliou sua capacidade de atuação e se profissionalizou com o recrutamento de seu quadro por meio de concurso público altamente competitivo e da estruturação da carreira de Auditor-Fiscal do Trabalho como uma das mais bem remuneradas do serviço público federal.

Meu contato com a organização iniciou-se durante projeto de pesquisa anterior, no qual tentei entender e explicar a variação nas formas de comportamento e atuação por parte dos fiscais do trabalho (PIRES, 2008). Ao longo de tal pesquisa, ${ }^{10}$ foi possível perceber a existência de dois sistemas diferentes que operavam simultaneamente pelos quais gestores no nível central supervisionavam o trabalho e desempenho dos Auditores-Fiscais do Trabalho no campo. O primeiro sistema de monitoramento segue os ditames da abordagem gerencialista e baseia-se em inspeções individuais e territorialmente circunscritas, as quais são avaliadas por meio de metas de desempenho individual (por exemplo, número de trabalhadores formalmente registrados por mês). Esse sistema envolve gratificação por desempenho, a qual pode alcançar até 45\% sobre o salário de auditor-fsical, sendo um terço resultante de desempenho individual e dois terços resultantes do desempenho coletivo do corpo de fiscais. Além deste, existia outro sistema, o qual se assemelha com a abordagem experimentalista, pois se baseia em grupos e equipes de fiscais que desenvolvem projetos

\footnotetext{
${ }^{10}$ A pesquisa de campo teve duração de aproximadamente 10 meses e foi realizada em três estados brasileiros (Minas Gerais, Bahia e Pernambuco) e envolveu coleta de dados, observação sistemática da atuação dos fiscais do trabalho e entrevistas. As entrevistas somaram um total de 115 com média de duas horas de duração. Quarenta e nove dessas entrevistas foram conduzidas com fiscais do trabalho nos três estados e na administração central em Brasília. Essas entrevistas e as estórias contadas pelos fiscais foram complementadas e confrontadas (trianguladas) com outras 65 entrevistas com atores envolvidos em cada caso específico, incluindo empresários, gerentes, trabalhadores, representantes de sindicatos de trabalhadores e patronais e membros de órgãos governamentais (por exemplo, Fundacentro, Ministério Público do Trabalho, agências de desenvolvimento etc.).
} 
organizados em torno de setores e atividades econômicas ou problemas específicos, como, por exemplo, trabalho infantil, terceirização ilícita, ou silicose no setor de mineração. Nesses casos, o trabalho dos grupos de fiscais é avaliado com base em relatórios parciais e finais nos quais são apresentados a dinâmica de trabalho dos grupos, os resultados obtidos e o desempenho deles em abordar ou solucionar problemas ligados ao cumprimento da legislação em setores e atividades econômicas como um todo.

A coexistência desses dois modelos de gestão na mesma organização criou uma oportunidade única para realização de pesquisa de campo e comparação entre essas duas formas de organização do trabalho de inspeção e gerenciamento da discricionariedade. ${ }^{11}$ Tal como ilustrado na Figura 1, por um lado, muitas variáveis importantes são mantidas constantes: a mesma organização e grupo de profissionais (isto é, mesma carreira, status, prerrogativas legais, salários etc.), fiscalizando as mesmas leis e normas no mesmo país e no mesmo Estado (Pernambuco), intervindo nos mesmos problemas (ex.: FGTS). ${ }^{12}$ Por outro lado, sob esse ambiente organizacional relativamente constante, existem dois métodos distintos para organização e supervisão do trabalho desempenhado pelos auditores-fiscais em campo (formas de gerenciamento da discricionariedade - NPM e EG). Portanto, as comparações sob esse quase experimento permitem "isolarmos” os efeitos da variável independente, isto é, modelos de gestão, sobre a rotina de trabalho dos fiscais e sobre os resultados de suas ações.

\footnotetext{
${ }^{11}$ Não se insere no escopo deste estudo nem constitui o objetivo desta análise explicar como esses dois diferentes modos de gestão da inspeção do trabalho emergiram no interior da mesma organização. Isto é objeto de outro artigo, no qual exploro como clivagens internas históricas entre facções de inspetores com diferentes interpretações do papel da inspeção do trabalho (ex.: arrecadação fiscal x desenvolvimento social) constituíram gradualmente modelos de inspeção alternativos, com suas respectivas estruturas organizacionais (práticas de inspeção, sistemas de avaliação de desempenho etc.). Como resultado desses conflitos internos, estimulados ou moderados pela administração central e atores externos (como OIT, Ministério do Planejamento, sindicatos, etc.), é possível observar um equilíbrio constantemente renegociado entre forças de fragmentação (coexistência de dois modelos de gestão) ou convergência (a supremacia de um modelo sobre o outro) nos últimos 15 anos.

${ }^{12}$ A seleção de casos para comparação é resultado de uma técnica para a construção da melhor amostra possível quando se trabalha com pequenas amostras em estudos qualitativos: amostragem estratificada e estatisticamente não representativa (TROST, 1986; MILES e HUBERMAN, 1994). O objetivo dessa estratégia de amostragem não é construir uma amostra representativa no sentido estatístico, mas maximizar a variação nas variáveis independentes. Diferentemente de amostras de estudos quantitativos que tendem a ser aleatórias (e gerar pouca variação interna quando a amostra é pequena), a amostra para a presente análise é intencional e estratificada; isto é, ela delimita subgrupos e facilita comparações entre casos com o intuito de explorar potenciais associações entre variáveis dependentes e independentes.
} 
Figura 1 - Desenho de Pesquisa e Seleção de Casos

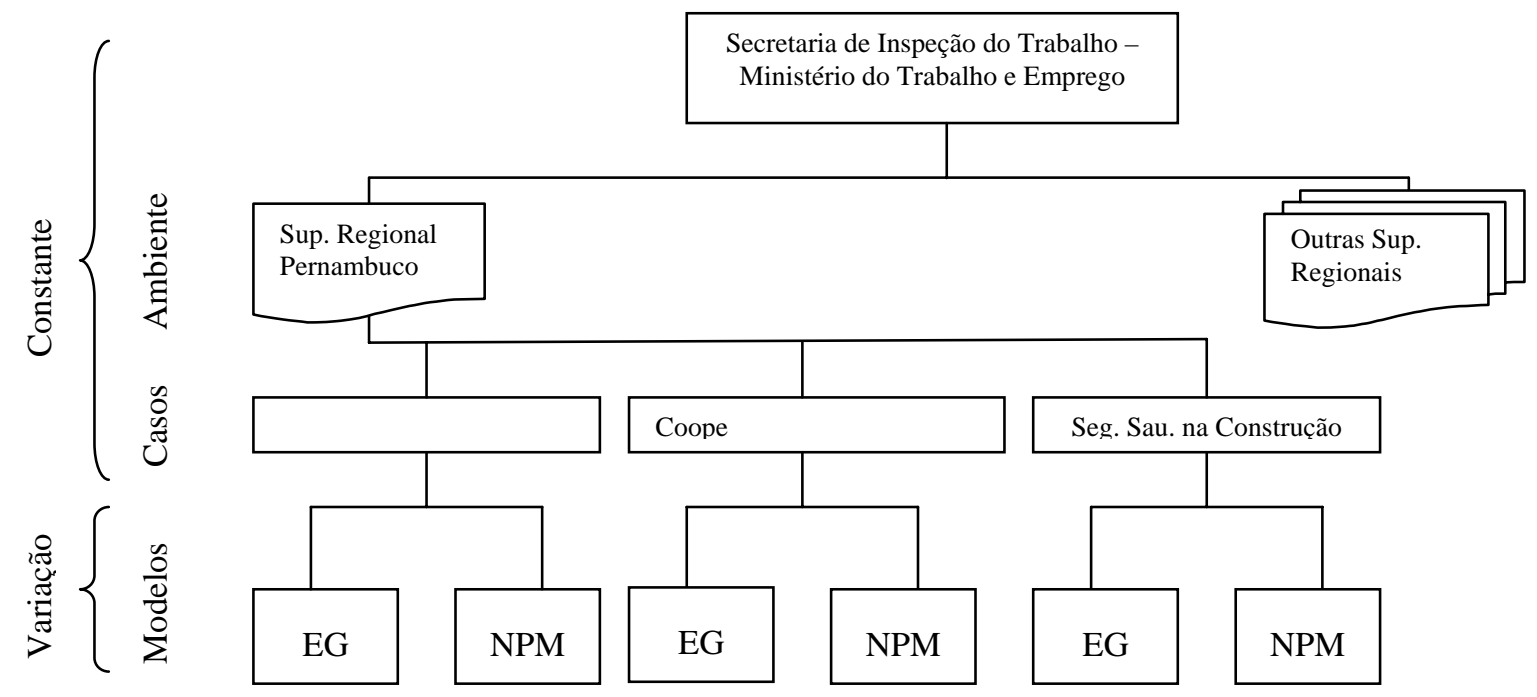

Nova gestão pública $x$ governança experimentalista: discricionariedade, rotinas de trabalho e resultados

Nesta seção, desenvolve-se a comparação do trabalho desenvolvido pelos auditores-fiscais do trabalho divididos em dois grupos - um gerenciado pelo modelo gerencialista e outro pelo modelo experimentalista. Por meio da observação e análise detalhada da atuação desses fiscais na mesma superintendência regional (Pernambuco), foi possível observar as semelhanças e diferenças na forma como esses dois grupos tratam um conjunto comum de problemas: a evasão ou sonegação do pagamento de FGTS, disseminação de cooperativas fraudulentas e acidentes ocupacionais na construção civil. Apesar do foco em Pernambuco, com o intuito de controlar diferenças relevantes em termos de ambiente político-econômico entre estados no Brasil, os problemas elencados e a coexistência dos dois modelos de gestão são igualmente presentes na atuação ordinária de fiscais do trabalho em outros estados. Para cada um dos três problemas, traçam-se comparações entre: a) a forma de organização do trabalho de inspeção de acordo com os dois modelos de gestão (por exemplo, procedimentos formais de inspeção, rotinas, e estratégias de fiscalização); e b) os impactos desses modelos nos resultados da inspeção do trabalho em Pernambuco. 


\section{Arrecadação de FGTS}

No Brasil, a legislação trabalhista estabelece o direito de trabalhadores formais ao Fundo de Garantia por Tempo de Serviço (FGTS) nas situações de demissão e aposentadoria. Todo mês, empregadores contribuem com $8 \%$ do salário do trabalhador para esse fundo, o qual acumula enquanto o trabalhador estiver empregado na mesma empresa. Sendo uma fonte importante de receita para o Governo Federal, o FGTS teve papel importante no ajuste fiscal dos anos 1990. O Ministério do Planejamento, Orçamento e Gestão pressionou e forneceu os devidos incentivos para que fiscais do trabalho focassem mais na sonegação e evasão de contribuições ao FGTS com o objetivo de incrementar a receita do Governo Federal. Assim, desde meados de 1990, a Secretaria de Inspeção do Trabalho (SIT) têm definido ano a ano a arrecadação de FGTS como uma das prioridades da inspeção do trabalho no país. Ainda assim, os esforços de arrecadação do FGTS por parte dos Auditores-Fiscais do Trabalho têm se organizado em duas formas distintas e coexistentes na Superintendência Regional do Trabalho em Emprego de Pernambuco (SRTE-PE).

A primeira estratégia tomou forma assim que o FGTS passou a ser considerado uma prioridade nacional para a fiscalização do trabalho e, seguindo os princípios da reforma gerencialista, a SIT determinou que cada fiscal em qualquer ponto do país teria que se submeter às metas de desempenho na arrecadação de tal receita governamental. A SIT instruiu os fiscais a verificarem o cumprimento da legislação relativa ao FGTS em toda e qualquer inspeção realizada por eles, mesmo quando motivadas por outros tipos de violação da legislação trabalhista. Os impactos da definição da arrecadação do FGTS como prioridade e da definição de metas de desempenho foram consideráveis: a arrecadação de tal receita pelos fiscais em todo país aumentou em quatro vezes no período de 1996 a 2005 (Tabela 1). 
Tabela 1 - Arrecadação total de FGTS pela fiscalização do trabalho no Brasil, 19962005

\begin{tabular}{|l|l|}
\hline Ano & Montante (em US\$) \\
\hline 1996 & $114.202 .231,20$ \\
\hline 1997 & $225.119 .264,87$ \\
\hline 1998 & $275.295 .590,83$ \\
\hline 1999 & $307.418 .537,60$ \\
\hline 2000 & $411.332 .339,08$ \\
\hline 2001 & $368.500 .063,09$ \\
\hline 2002 & $480.284 .704,85$ \\
\hline 2003 & $398.969 .690,00$ \\
\hline 2004 & $414.483 .525,00$ \\
\hline 2005 & $411.443 .815,00$ \\
\hline
\end{tabular}

Fonte: MTE/SIT.

Ao longo desse período, os fiscais do trabalho em Pernambuco (da mesma forma que em outros estados brasileiros) têm organizado seu trabalho por meio de um sistema de zoneamento. Os gestores estaduais do serviço designam pares de fiscais do trabalho a uma área geográfica no estado. Esses pares de fiscais têm a responsabilidade de cobrir sua área por meio de inspeções nas empresas localizadas nessas regiões na busca por violações da legislação trabalhista. As fiscalizações conduzidas sob esse regime tendem a focar empresas e problemas individuais e não seguem nenhum tipo de estratégia mais compreensiva de planejamento, variando inclusive entre os diversos pares de fiscais. Nesses casos, as fiscalizações são motivadas principalmente em resposta a denúncias e reclamações recebidas de trabalhadores individuais e também de sindicatos (SILBEY, 1980; 1981). Além de terem que cumprir com metas de arrecadação de FGTS, cada auditorfiscal também tem que fiscalizar um número mínimo de estabelecimentos por mês. Essas metas de desempenho (arrecadação e número de estabelecimentos) conjuntamente criam incentivos para que fiscais alcancem suas metas de desempenho concentrando suas fiscalizações em empresas relativamente pequenas e com pequenos débitos de FGTS, pois as fiscalizações nessas empresas tendem as ser mais fáceis do ponto de vista técnico e também mais célere, deixando de lado firmas de maior porte com débitos potencialmente mais complicados. Como resultado, um grande número de auditores-fiscais, se não a totalidade destes, tem investido grande parte do seu tempo em apenas um problema concernente à fiscalização do trabalho: a arrecadação de FGTS. O resultado final peca na 
eficiência da arrecadação de FGTS por fiscalização (em US\$) quando comparado aos resultados de uma estratégia adotada por um pequeno grupo de fiscais trabalhando sob um sistema de gestão de desempenho alternativo (Tabela 2).

Em 2006, a SIT autorizou a criação de um projeto piloto na Superintendência Regional do Trabalho e Emprego de Pernambuco (SRTE-PE): o grupo operacional do FGTS ou o GOFGTS. ${ }^{13}$ Quatro, do total de 145 auditores-fiscais da SRTE-PE, foram designados a formar o GO-FGTS. Ao formarem o grupo, tais ficais foram simultaneamente desobrigados a cumprir as metas de desempenho imposta aos demais fiscais. A SIT classificou os quatro fiscais como desempenhando "atividade especial" e, assim, provendo-os imunidade com relação às medidas de desempenho típicas do modelo gerencialista. Além de liberá-los de metas de desempenho necessariamente quantitativas e predefinidas e de procedimentos de inspeção padronizados, o grupo de fiscais também não precisa obedecer às restrições em termos de área geográfica para sua atuação. Em suma, a esse grupo de fiscais foi concedido maior espaço organizacional para desenvolver táticas de inspeção com um foco estratégico nas atividades econômicas e empresas com débitos de FGTS potencialmente maiores.

A primeira medida adotada pelo GO-FGTS foi estreitar relações com a CEF (Caixa Econômica Federal), instituição responsável pela administração dos depósitos ao FGTS. O grupo de auditores-fiscais requisitou acesso aos dados com os quais poderiam desenvolver um sistema informatizado capaz de identificar as empresas no Estado de Pernambuco com maiores débitos e prever os setores com maior propensão à evasão e sonegação de FGTS. Uma vez desenvolvida tal base de dados, o GO-FGTS produziu uma lista dos 1.000 estabelecimentos em Pernambuco com o maior potencial para arrecadação de FGTS a partir do universo de 62.000 empresas formalmente registradas no Estado. Essas 1.000 empresas empregam sozinhas aproximadamente $40 \%$ de toda a força de trabalho formal do Estado; cada uma delas individualmente possui contingentes de trabalhadores relativamente grandes e operam em setores que tradicionalmente violaram as normas relativas ao fundo de garantia (exemplos incluem os setores de bebidas, hotéis, beneficiamento de cana-deaçúcar e derivados, entre outros). O foco nessa amostra de firmas tornou a tarefa de

${ }^{13}$ Em 2007, o projeto é ampliando e a SIT torna compulsória a criação de grupos operacionais como este em todas as 27 Superintendências Regionais.

CADERNOS GESTÃO PÚBLICA E CIDADANIA, V. 14, N. 54 - JAN./JUNHO DE 2009 
fiscalização manejável e, de acordo com um dos membros do grupo operacional, “(...) podemos não apenas fiscalizar, mas também monitorar o cumprimento da legislação em 1.000 empresas". Além do monitoramento, o foco nesse grupo de empresas permitiu ao GO-FGTS a customização de estratégias de fiscalização para cada atividade ou setor da economia, por meio da adaptação de procedimentos e aproveitamento de oportunidades oferecidas pela estrutura e dinâmica de cada setor, com o objetivo de produzir maiores impactos em termos do cumprimento da lei e da arrecadação de receitas para o Estado.

Anteriormente ao desenvolvimento da base de dados do GO-FGTS, uma fiscalização de FGTS realizada por pares de fiscais em uma empresa de grande porte (com aproximadamente 3.000 funcionários) levaria cerca de oito meses apenas para conclusão da auditoria e levantamento de irregularidades e débitos. Consequentemente, grandes empresas com débitos complexos eram frequentemente ignoradas ou fiscalizadas de forma apenas superficial. Com a nova base de dados e ferramentas de análise desenvolvidas pelo GO-FGTS, o mesmo processo de identificação de irregularidades em firmas do mesmo porte leva apenas diversas horas para ser concluído. Com a obtenção mais célere de tais informações, os auditores-fiscais já realizam as fiscalizações in loco com números e evidências documentais de irregularidade que indicam o montante e as potenciais causas do débito. Assim, durante as fiscalizações, as empresas podem optar por sanar o débito imediatamente, negociar um cronograma de pagamentos, ou recusar o pagamento e receber as respectivas penalidades (multas administrativas). Com o objetivo de incrementar ainda mais o poder de sanção em suas operações, o grupo de fiscais estabeleceu parceria com os procuradores do tesouro nacional, os quais têm a prerrogativa de abrir processos legais que frequentemente resultam em multas e penalidades ainda mais severas.

Finalmente, em contraposição à abordagem responsiva a partir da qual os pares de fiscais atuando em seu distrito geográfico lidam com empresas individualmente e isoladamente (uma de cada vez), o GO-FGTS realiza reuniões periódicas para discutir os resultados de suas ações e rever as práticas empregadas em busca do aprimoramento constante de suas ações. Por meio de trocas de experiência e interações praticamente contínuas entre os membros do grupo e parceiros externos sobre as vantagens e desvantagens de diferentes estratégias de fiscalização, o GO-FGTS construiu um repertório de táticas que têm provado serem eficazes e eficientes. Além disso, por meio dessas conversas, os membros 
desenvolvem procedimentos padronizados para cada setor ou atividade econômica, evitando inconsistências derivadas das inspeções realizadas por diferentes fiscais. Essa padronização por setor apresenta impactos positivos também para as empresas: cria previsibilidade da ação fiscal e a sensação de justiça quando empresários descobrem que seus concorrentes imediatos foram fiscalizados com base nos mesmos procedimentos e orientações. A ação fiscal mais coerente e uniforme, em comparação com a atuação isolada dos pares de fiscais trabalhando sob o regime de metas de desempenho em distritos geográficos, também contribui para aumentar a legitimidade e o número de decisões favoráveis do judiciário quando este aprecia recursos interpostos por empresas insatisfeitas com a fiscalização sofrida.

É importante notar que os avanços alcançados pelo GO-FGTS vão muito além da focalização estratégica de um grupo de empresas maiores. Parte importante da experiência do grupo operacional são as interações contínuas com parceiros estratégicos, tais como a CEF e os procuradores do tesouro nacional. Tais interações resultaram na construção de ferramentas de diagnóstico mais precisas e na customização de táticas de fiscalização para cada atividade econômica, as quais cumulativamente vêm produzindo fiscalizações com maiores impactos. Quando comparado aos resultados do sistema de pares de fiscais por zoneamento geográfico (Tabela 2), o GO-FGTS, que emprega apenas 3\% (4) dos fiscais na SRTE-PE, arrecadou 65\% de todo o FGTS arrecadado por todos os fiscais no Estado. Após a criação do grupo operacional, a arrecadação de FGTS via fiscalização em Pernambuco dobrou de 2005 a 2006. Em 2007, o GO-FGTS de Pernambuco arrecadou o maior volume de FGTS em termos absolutos (maior até do que o volume arrecadado em estados mais industrializados) e beneficiou o maior número de trabalhadores dentre todas as Superintendências Regionais. À medida que os membros do grupo foram liberados do regime de metas de desempenho predefinidas e passaram a gozar de maior autonomia no desenvolvimento de ações mais complexas, tais como as que envolveram colaborações com outras organizações governamentais, eles se tornaram mais produtivos e passaram a utilizar cada vez menos recursos internos. 
Tabela 2 - Comparação entre os resultados da arrecadação de FGTS pelos fiscais do trabalho em Pernambuco, 2007

\begin{tabular}{|l|c|c|c|c|c|c|c|}
\hline & $\begin{array}{c}\text { N. }{ }^{\circ} \text { de } \\
\text { fiscais }\end{array}$ & $\begin{array}{c}\text { Empresas } \\
\text { fiscalizadas }\end{array}$ & $\begin{array}{c}\text { Arrecadação total } \\
\text { de FGTS via } \\
\text { fiscalização (US\$) }\end{array}$ & $\begin{array}{c}\text { \% do total de } \\
\text { empresas } \\
\text { fiscaliz. }\end{array}$ & $\begin{array}{c}\text { \% do total } \\
\text { de FGTS } \\
\text { arrecad. }\end{array}$ & $\begin{array}{c}\text { FGTS } \\
\text { arrecadado } \\
\text { / empresa } \\
\text { média (US\$) }\end{array}$ & $\begin{array}{c}\text { FGTS } \\
\text { arrecadado p/ } \\
\text { fiscal. - média } \\
\text { (US\$) }\end{array}$ \\
\hline $\begin{array}{l}\text { Zoneamento } \\
\text { performanc } \\
\text { e individual) }\end{array}$ & 141 & 12,959 & $12,583,883.16$ & $98.57 \%$ & $34.81 \%$ & 971.05 & $89,247.40$ \\
\hline GO-FGTS & 4 & 188 & $23,568,255.16$ & $1.43 \%$ & $65.19 \%$ & $125,363.05$ & $5,892,063.79$ \\
\hline $\begin{array}{l}\text { Total } \\
\text { Pernambuco }\end{array}$ & 145 & 13,147 & $36,152,137.96$ & $100 \%$ & $100 \%$ & $2,749.84$ & $249,325.09$ \\
\hline Total Brasil & 3,174 & 285,462 & $566,486,244.08$ & - & - & $1,984.45$ & $178,477.08$ \\
\hline
\end{tabular}

Fonte: MTE/SIT e SRTE-PE.

\section{Cooperativas Fraudulentas e Terceirização Ilegal}

Cooperativas de produtores e trabalhadores já existem no Brasil desde 1891, mas receberam reconhecimento legal apenas nos anos 1970, sendo que a Constituição de 1988 consolidou e estimulou tal estrutura de trabalho e produção. Entretanto, em 1994, mudanças aparentemente pequenas introduzidas em um parágrafo da CLT (Consolidação das Leis do Trabalho) criaram ambiguidades e incertezas. Desde então, cooperativas têm sido largamente empregadas como um método de baixo custo para empresas terceirizarem suas atividades intensivas em trabalho (por exemplo, serviços de limpeza e conservação, serviços administrativos, ou até mesmo médicos e enfermeiros em hospitais). No contexto de reestruturação global da produção, as empresas vêm sistematicamente terminando contratos de trabalho com seus funcionários e recontratando os mesmos por meio da celebração de contratos de serviço com cooperativas de trabalho. Para as empresas, tal terceirização representa uma forma de evitar a legislação e os encargos trabalhistas; para os trabalhadores, representa perda dos benefícios e direitos trabalhistas, uma vez que se tornam membros, e não empregados, de uma cooperativa prestadora de serviços.

Interpretações e decisões recentes do Tribunal Superior do Trabalho (TST), vide súmula 311, desautorizam a utilização de cooperativas, assim como de empresas, para a 
terceirização de atividades-fim (por exemplo, o projetista de software em empresas de informática) e para a mera intermediação de trabalho, como no caso de cooperativas que não produzem nada além da força de trabalho de seus membros. Como resultado da percepção de que muitas empresas têm recorrido a cooperativas como uma forma de reduzir custos, a fiscalização do trabalho tem devotado recursos e ações no sentido de combater a precarização do trabalho que frequentemente ocorre nesses arranjos. Tal como no exemplo anterior da arrecadação do FGTS, os Auditores-Fiscais do Trabalho na SRTEPE têm lidado com o problema das cooperativas fraudulentas a partir de duas abordagens bem distintas.

A primeira delas também é baseada na organização do trabalho de inspeção a partir de pares de fiscais que atuam no sistema de zoneamento geográfico. Da mesma forma que na arrecadação de FGTS, fiscais têm que alcançar metas de desempenho pré-estabelecidas em termos da formalização de vínculos empregatícios. À medida que empresas têm recorrido crescentemente à terceirização do trabalho para cooperativas, os fiscais da SRTE-PE vêm percebendo reduções expressivas na formalização do trabalho - isto é, trabalhadores formais têm sido demitidos e transformados em membros de cooperativas prestadoras de serviço - prejudicando os fiscais da SRTE-PE no desempenho de sua meta de formalização de empregos.

Entretanto, não é fácil lidar com tais cooperativas fraudulentas sob as fiscalizações rápidas e mecanizadas propagada pelo sistema de monitoramento no desempenho de metas quantificadas e predefinidas. Assim, uma vez que os fiscais sob o regime de pares em zoneamento identificam tais fraudes na relação trabalhista, eles tendem a lidar com o problema de forma não uniforme - por exemplo, com a coleta de registros de contabilidade in loco ou por meio de solicitação formal para apresentação de documentos, ou a entrevista de trabalhadores durante a jornada de trabalho ou fora do local de trabalho, ou ainda com a investigação dos registros das cooperativas subcontratadas ou apenas das empresas contratantes. A inconsistência na atuação dos fiscais em face de tal problema complexo leva a autuações e notificações que são facilmente contestadas e derrubadas via recurso por parte de empresas. Às dificuldades em lidar com o problema somam-se o crescente número de denúncias e reclamações por parte de trabalhadores e sindicatos em relação à disseminação de cooperativas fraudulentas e as demandas sobre os fiscais vindas do 
Ministério Público do Trabalho por uma maior efetividade no combate a fraude nas relações do trabalho.

Em resposta a essas demandas externas e também à pressão interna de um grupo informal de fiscais que já vinha enfrentando a questão das cooperativas fraudulentas em Pernambuco desde 2000, a SIT e a SRTE-PE autorizaram a criação de um grupo de sete fiscais: a Equipe de Combate a Fraude nas Relações de Emprego (ECOFREM). Reconhecendo a complexidade do problema e a necessidade de desenvolvimento de estratégias especiais, a SIT concedeu aos membros da equipe status de "atividade especial”, isentando-os do sistema geral de mensuração de desempenho. Para ser efetivo, o trabalho da equipe demandava um processo mais aberto e investigações detalhadas para a produção de provas documentais que caracterizem a fraude, não podendo assim ser executado tendo por orientação metas e procedimentos de investigação predefinidos. Com o objetivo de desenvolver casos sólidos contra empresas e suas cooperativas fraudulentas, o grupo de fiscais precisava utilizar táticas diversificadas como a coleta de testemunho e procurações de trabalhadores, negociações com empresários, parcerias com sindicatos, associações profissionais e juízes e procuradores federais. Para supervisionar a autonomia concedida aos membros do ECOFREM, gestores da SRTE-PE avaliam periodicamente o desempenho da equipe por meio de relatórios escritos que detalham a atuação do grupo e seus resultados, além de incluir justificativas para sua continuidade.

Desde a sua criação, a ECOFREM tem mantido intensos diálogos com os procuradores do Ministério Público do Trabalho (MPT), que contribuem para a caracterização legal das fraudes, e com sindicatos de trabalhadores, que fornecem informações importantes sobre práticas de contratação em setores específicos, com o intuito de desenvolver estratégias e procedimentos compartilhados para intervenção e monitoramento. A aplicação de tais procedimentos acordados entre os parceiros contribuiu para um tratamento mais uniforme de empresas no mesmo setor e para fortalecer a consistência legal das intervenções. Desde a criação da ECOFREM, nenhuma autuação expedida pelos fiscais do trabalho foi derrubada nos tribunais do trabalho em Pernambuco. Além disso, as estratégias e práticas de investigação são periodicamente reavaliadas pelo grupo de fiscais e procuradores do MPT - estes últimos também contribuem para ampliação do poder de sanção por meio de Termos de Ajuste de Conduta (TAC) e suas respectivas penalidades. Como resultado das 
interações e trocas entre esses agentes, a ECOFREM começou a implementar operações voltadas para cobrir todo um setor de atividade econômica (e não empresas isoladas). O principal objetivo dessas operações é promover mudança nas práticas de contratação e gestão de pessoal em setores como um todo, setor por setor, em especial aqueles com um número grande de empresas tradicionalmente envolvidas em formas ilícitas de terceirização.

De 2001 a 2002, a ECOFREM desenvolveu uma operação na indústria do software em Recife, uma vez quer perceberam que $32 \%$ de todas as denúncias recebidas sobre cooperativas vinham desse setor. De acordo com a coordenadora da equipe:

"O sindicato [SINDPD] veio até nós e ao MPT trazendo os resultados de uma análise que identificava que o setor estava crescendo, mas que o emprego formal e a massa salarial estavam diminuindo. Tinha alguma coisa acontecendo ali. Eles já tinham ouvido falar de alguns trabalhadores sobre o crescimento das cooperativas no setor. A gente sabia também por experiência própria que nos últimos anos os trabalhadores do setor eram em sua maioria formais.”

Grande parte das empresas do setor vinha recorrendo às cooperativas como uma estratégia de corte de custos de produção, uma vez que enfrentavam intensa competição com as empresas de tecnologia de informação da Índia. À medida que as investigações evoluíram, o grupo de fiscais percebeu que quase a totalidade das empresas do setor tinha algum tipo de esquema envolvendo a terceirização de projetistas de softwares, engenheiros de sistemas e outros profissionais sob a forma de cooperativas. Esses funcionários trabalham todos os dias no mesmo escritório, subordinando-se ao mesmo chefe, elementos que constituem uma relação de emprego, segundo a interpretação de juízes do trabalho.

Os auditores-fiscais e seus parceiros tinham consciência de que o custo de formalização de todos esses trabalhadores (retroativamente) era por demais elevado para as empresas de pequeno e médio porte que enfrentavam competição internacional, podendo inclusive excluí-las desse mercado. No entanto, eles também não poderiam ignorar tal situação. Em busca da conciliação dos diversos interesses das firmas, dos trabalhadores e do Estado, o 
grupo de fiscais coordenou uma série de encontros com 35 empresas. Em um período de oito meses e depois de mais de 50 reuniões, eles negociaram com as empresas um cronograma para ajustamento por meio do qual empresas iriam gradualmente recontratar seus funcionários diretamente à medida que as demandas por produção aumentassem no curto prazo. Entre 2001 e 2003, a operação no setor levou a recontratação de 2.215 trabalhadores anteriormente envolvidos em cooperativas fraudulentas.

Entre 2002 e 2006, a ECOFREM desenvolveu uma operação no setor de saúde. Além de receber um número significativo de denúncias por parte de trabalhadores, o grupo de fiscais já havia diagnosticado um problema delicado no setor por meio da análise de estatísticas oficiais sobre o encerramento de contratos de trabalho formais em hospitais e clínicas, especialmente para médicos, enfermeiros e outros profissionais de saúde. Em Recife, hospitais, clínicas de fisioterapia e laboratórios há muito vêm terceirizando seus funcionários de ponta para cooperativas de provisão de serviço. Como resultado dessa "cultura de contratação" no setor, profissionais de saúde vêm perdendo proteção legal contra abusos de horas extras e direitos de descanso e férias periódicas. Esses profissionais frequentemente sofrem de privação de sono devido a plantões duplos, dependência química de estimulantes e problemas mentais, os quais cumulativamente prejudicam a qualidade do tratamento de pacientes. Em um esforço de mudar práticas de contratação e gestão de pessoal já corriqueiras nesse setor, a ECOFREM ministrou uma série de workshops, frequentados por mais de 195 profissionais, para explicar a legislação e o que gerentes de instituições de saúde poderiam fazer para cumpri-la. Além disso, os membros da ECOFREM fiscalizaram 64 estabelecimentos. Em parceira com o Ministério Público do Trabalho, a equipe de fiscais promoveu 177 Termos de Ajustamento de Conduta (TAC), envolvendo empresas, associações profissionais e sindicatos. Em um período de quatro anos, eles formalizaram 2.067 trabalhadores, incluindo médicos, enfermeiros e assistentes.

Além dos resultados imediatos da recontratação de milhares de trabalhadores, essas operações que abrangem setores específicos como um todo produzem efeitosdemonstração. Por exemplo, seguindo o sucesso das ações da ECOFREM nos setores de informática e saúde, a SIT criou uma operação nacional em 2006 para investigar fraudes semelhantes em instituições financeiras em sete estados diferentes, inspirando-se e buscando apoio técnico na experiência pernambucana. Além disso, os fiscais perceberam, 
com base em informações providas por trabalhadores e por base de dados oficiais (por exemplo, o CAGED), que muitas outras empresas passaram a cumprir a lei após ouvirem dizer que uma série de empresas vinha sendo fiscalizada e punida por irregularidades. Por exemplo, um grupo de hospitais em Recife que ainda não havia sido fiscalizado registrou mais de 300 médicos nos meses imediatamente seguintes à operação da ECOFREM. Além de criar um procedimento efetivo para lidar com a complexa questão da disseminação de cooperativas fraudulentas como artifício para evitar a legislação trabalhista, os membros da ECOFREM ainda assim apresentam desempenho superior aos seus pares que atuam sob o sistema do zoneamento com metas de desempenho individuais. Enquanto cada um desses fiscais formaliza em média 15 postos de trabalho por mês, cada membro da ECOFREM formaliza em média 25 postos de trabalho por mês (dados para 2007).

Segurança na construção: a Comissão Tripartite de Pernambuco

Tradicionalmente, a construção civil é ao mesmo tempo uma das maiores fontes de emprego e acidentes ocupacionais, devido aos riscos inerentes à atividade, assim como às condições de segurança e saúde precárias. No Brasil, aproximadamente 5,4 milhões de trabalhadores encontram-se oficialmente empregados no setor, respondendo por $13 \%$ de todos os acidentes ocupacionais fatais no país em 2004, de acordo com a Organização Internacional do Trabalho. De meados ao final dos anos 1990, Pernambuco observou uma expansão rápida de sua indústria de construção, que em 2000 passou a empregar aproximadamente 48.500 trabalhadores, não acompanhada pelas melhorias necessárias no que diz respeito às condições de segurança. Consequentemente, o Estado liderou o ranking de número de acidentes na construção civil no Brasil (26 mortes em 1996 e 15 em 2000). Quedas e choques elétricos eram as principais causas dessas mortes. Tal como nos dois casos já discutidos anteriormente, duas estratégias diferentes para a fiscalização de condições de saúde e segurança na construção civil evoluíram lado a lado na SRTE-PE.

Em Pernambuco, tal como em outros estados, os auditores-fiscais especializados em saúde e segurança do trabalho já vêm organizando seu trabalho de fiscalização com foco em setores econômicos desde o início dos anos 1990, antes mesmo os fiscais especializados na legislação trabalhista começarem a trabalhar dessa forma. Em reconhecimento aos riscos 
naturalmente associados com o trabalho na construção, os fiscais de saúde e segurança de Pernambuco vêm dedicando, em média, 30\% de suas fiscalizações ao setor construção. Mesmo que esses fiscais já se organizassem com um foco estratégico em setores de maior risco, suas fiscalizações, no entanto, eram conduzidas por pares de fiscais orientados por metas quantitativas, como um número $x$ de inspeções, resultando em um número $y$ de autuações e cobrindo um número $z$ de trabalhadores por mês ou ano.

Sob esse modelo e em resposta ao alto número de acidentes na construção, os fiscais de Pernambuco se tornaram uns dos mais severos na aplicação de sanções - tais como embargo e interdição, além de multas e notificações - dentre seus pares no Brasil. Entretanto, como um auditor-fiscal da área narrou “(...) nós viemos a acreditar ao longo do tempo que a utilização de sanções apenas não ataca as raízes do problema e não diminui os riscos aos quais os trabalhadores ficam expostos”. Os fiscais perceberam que, em muitos casos, empresas do setor preferiam recorrer ou pagar as multas sem alterar em nada as condições de trabalho nos seus canteiros de obra. Em outras palavras, as inspeções periódicas e as multas passaram a ser tratadas por empresários do setor como custos normais do processo produtivo.

Entretanto, uma forma alternativa de organização do trabalho de inspeção na construção civil emergiu em Pernambuco. Em 1998, A Comissão Tripartite Nacional, que elabora e revê as normas de saúde e segurança no país, fez alterações na norma da construção civil e permitiu, ainda que não tornando compulsória, a criação de comissões tripartites locais (CTLs) nas Superintendências Regionais. A SRTE-PE saiu na frente com a criação de sua CTL em 1999. A comissão tripartite local em Pernambuco reúne os auditores-fiscais, os sindicatos de trabalhadores, o sindicato patronal e outros órgãos governamentais (como a Fundacentro - o instituto nacional de pesquisa em saúde e segurança ocupacional - e o Ministério Público do Trabalho). Duas vezes por mês, desde 1999, os representantes desses grupos discutem ao redor da mesma mesa matérias relativas à saúde e segurança ocupacional na construção civil. ${ }^{14}$ Desde a sua criação, a CTL se tornou o principal canal de interação entre fiscais, sindicalistas e construtores.

\footnotetext{
${ }^{14}$ Todos os meses, eles se reúnem primeiramente para uma reunião fechada e posteriormente para uma reunião aberta ao público, em estilo de seminário.
} 
Em minhas entrevistas com representantes dos trabalhadores e das empresas construtoras, praticamente todos se referiram à CTL como um local para troca de informações sobre saúde e segurança no setor. Tal como pude observar em algumas das reuniões dessa comissão, as discussões são geralmente acaloradas e com frequência deflagram conflitos. Porém, na maioria das vezes, os fiscais conseguem mediar o debate de forma a levar à celebração de acordos entre as partes. $\mathrm{O}$ fato de essas reuniões regulares terminarem frequentemente com acordos bem-sucedidos em quase a totalidade dos últimos dez anos é ainda mais impressionante se levarmos em consideração que, antes da criação da CTL, a relação entre os sindicatos patronal e de trabalhadores era tensa e até mesmo violenta, envolvendo constantes greves, acusações públicas e ações na justiça. Antes da CTL, sindicato e empresas limitavam seus encontros à negociação anual de salários e outras negociações ad hoc para solucionar greves e urgências. Atualmente, esses atores sentam na mesma mesa e negociam os detalhes da implementação das normas de saúde e segurança ocupacional nos canteiros de obras. Finalmente, os membros da comissão acordaram que todas as questões decididas pela CTL automaticamente se tornam itens do acordo coletivo anual do setor.

Para além de uma nova dinâmica de interação entre as partes envolvidas, um caso ilustra bem as consequências positivas da organização do trabalho de inspeção a partir da CTL (em comparação com estratégias ordinárias de fiscalização). Dado o elevado número de acidentes fatais por eletrocussão nos canteiros de obra, a CTL já vinha promovendo uma discussão interna e trabalhando na identificação de potenciais medidas para mitigação do problema. Porém, os fiscais envolvidos, assim como os trabalhadores e empresas, não sabiam exatamente que medidas tomarem para reduzir os acidentes para além da notificação e autuação dos infratores. Avanços significativos somente passaram a ocorrer quando o representante da Fundacentro - quem havia recentemente tomado conhecimento da experiência japonesa na redução de tais acidentes via periódicos especializados convidou um representante da Siemens no Brasil para fazer uma apresentação sobre seus dispositivos de segurança para circuitos elétricos. O convidado apresentou uma versão do dispositivo diferencial residual (DR) que sua empresa iria lançar no mercado não só com características mais apropriadas aos canteiros de obras, mas também com preços reduzidos (variando de US\$ 20 a US\$100, cada) em relação às linhas industriais do mesmo produto. 
Uma vez instalado no circuito elétrico de um canteiro de obras, o DR corta o fluxo de energia toda vez que detecta fuga ou curto-circuito, precisamente o que ocorre na ocasião de choques elétricos. Ao cortar a força, o DR evita a eletrocussão de trabalhadores e outros potenciais acidentes envolvendo energia elétrica.

Após a descoberta do dispositivo tecnológico, o próximo desafio foi o de aprimorar as condições dos circuitos elétricos nos canteiros, pois o DR falha (causando cortes de energia constantes) se instalado em circuitos de baixa qualidade. Assim, os fiscais convenceram um empresário a ser o pioneiro na adaptação dos circuitos para o DR, uma vez que os empresários do setor não sabiam como fazer o dispositivo funcionar adequadamente. Em conjunto, os fiscais e o empresário conseguiram, com o apoio da Federação das Indústrias do Estado de Pernambuco (FIEPE), um curso de capacitação para eletricistas e, assim, fizeram os ajustes necessários na infraestrutura e rotinas de operação de um canteiro de obras, tornando a implantação do DR viável para todas as empresas do setor.

Como consequência desse processo exploratório (open-ended), o qual durou aproximadamente três anos, envolvendo discussões, testes e adaptação, e formação de consenso entre os membros da CTL sobre a implantação do DR, os auditores-fiscais obtiveram evidências e apoio suficiente para disseminar a implantação do dispositivo na construção civil em Pernambuco. ${ }^{15}$ Em fevereiro de 2004, a CTL deliberou que todos os novos projetos de construção deveriam prever a instalação do DR. Um survey conduzido em 2006 pelo sindicato patronal (Sinduscon-PE, 2007) revelou que apenas $0,71 \%$ dos novos projetos (em uma amostra de 700 projetos e canteiros de obra) não previam ou não possuíam DR instalado. Em decorrência disso, em 2006, 2007 e 2008, a média de acidentes fatais caiu para dois por ano, com ocorrências registradas apenas em empresas que não cumpriram com a resolução da CTL.

Além de reduzir significativamente o risco de acidentes por choque elétrico, a implantação da solução desenvolvida no âmbito da comissão tripartite também apresentou efeitos positivos em termos da melhoria de qualidade dos circuitos elétricos nos canteiros de obra, um pré-requisito para a instalação do DR. O cumprimento das normas e legislação

\footnotetext{
${ }^{15}$ Um caso semelhante gestado no âmbito da CTL diz respeito às adaptações técnicas em elevadores de passageiros e cargas nos canteiros de obra de forma a minimizar quedas e outros acidentes envolvendo o equipamento.
} 
pertinente aumentou substancialmente entre 1997 e 2006 e, em decorrência da forma como tal resultado foi obtido, canteiros de obras se tornaram também mais eficientes no uso de energia elétrica, evitando desperdício devido a más instalações e reduzindo o gasto das empresas com energia.

Figura 2 - Canteiros de obras com instalações elétricas inadequadas

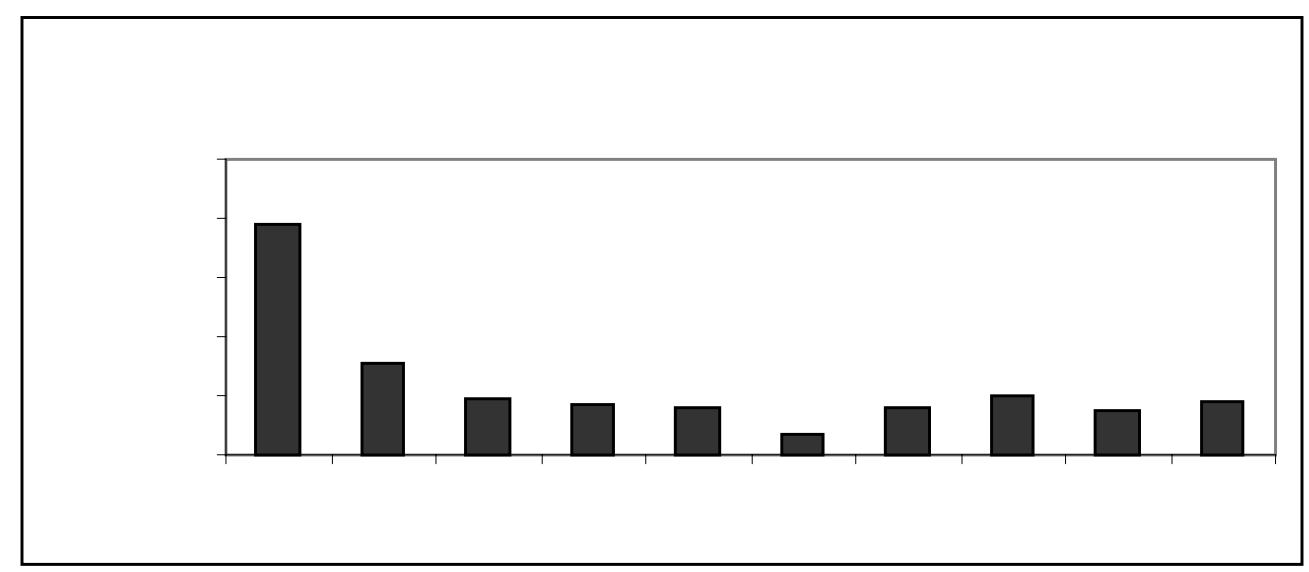

Fonte: elaborado pelo autor com base nos dados da Sinduscon (2007).

\section{Discussão: modelos de gestão, comportamento burocrático e resultados}

O Quadro 1 sintetiza as principais conclusões das comparações entre os três pares de casos descritos na seção anterior e no interior delas. Com base nas evidências empíricas apresentadas (semelhanças entre os diferentes casos nas linhas e diferenças entre modelos de gestão nas colunas), torna-se claro que os dois métodos para organização do trabalho de inspeção (gerencialista $x$ experimentalista) envolvem ferramentas significativamente diferentes por meio das quais supervisores monitoram o desempenho de seus subordinados, assim como práticas, rotinas e estratégias de fiscalização bastante diversas. A análise comparativa também sugere uma associação causal plausível entre formas de gerenciamento da discricionariedade e resultados da inspeção do trabalho no Brasil. 


\section{Quadro 1 - Comparações entre casos}

\begin{tabular}{|c|c|c|c|c|}
\hline \multirow{2}{*}{$\begin{array}{l}\text { Elementos de } \\
\text { comparação }\end{array}$} & \multirow{2}{*}{$\begin{array}{c}\text { Modelos de gestão } \\
\text { da fiscalização }\end{array}$} & \multicolumn{3}{|c|}{ Casos ou objetos de inspeção } \\
\hline & & $\begin{array}{l}\text { Arrecadação de } \\
\text { FGTS }\end{array}$ & $\begin{array}{l}\text { Cooperativas } \\
\text { Fraudulentas }\end{array}$ & $\begin{array}{l}\text { Segurança e } \\
\text { Saúde na } \\
\text { Construção Civil }\end{array}$ \\
\hline \multirow{2}{*}{$\begin{array}{l}\text { Account- } \\
\text { ability / } \\
\text { controle e } \\
\text { supervisão }\end{array}$} & Gerencialista & \multicolumn{3}{|c|}{$\begin{array}{l}\text { Mensuração de resultados predefinidos - "FGTS/fiscal”; "número de } \\
\text { estabelecimentos fiscalizados"; "número de contratos } \\
\text { formalizados/fiscal”; "número de autuações/mês" etc. }\end{array}$} \\
\hline & Experimentalista & \multicolumn{3}{|c|}{$\begin{array}{l}\text { Avaliação de relatórios parciais da operação, justificando sua } \\
\text { continuidade ou a revisão de metas e procedimentos de inspeção } \\
\text { (baseados em dados quantitativos e qualitativos). }\end{array}$} \\
\hline \multirow{2}{*}{$\begin{array}{l}\text { Práticas, } \\
\text { rotinas e } \\
\text { estratégias de } \\
\text { inspeção }\end{array}$} & Gerencialista & \multicolumn{3}{|c|}{$\begin{array}{l}\text { Sistema de zoneamento: Fiscalização responsiva e aleatória de } \\
\text { estabelecimentos em áreas geográficas. Procedimentos não uniformes } \\
\text { (inconsistentes) para empresas do mesmo setor. Investigações pouco } \\
\text { detalhadas e sem produção de evidência legal. }\end{array}$} \\
\hline & Experimentalista & \multicolumn{3}{|c|}{$\begin{array}{l}\text { Interações contínuas entre fiscais e parceiros relevantes (co-produção e } \\
\text { revisão de estratégias e planos de inspeção etc.). Uso de ferramentas de } \\
\text { diagnóstico (ex.: bases de dados, parceiros externos etc.). Operações } \\
\text { cobrindo todo um setor específico (foco estratégico em setores de risco). } \\
\text { Procedimentos e táticas de inspeção customizadas por setor (com } \\
\text { padronização de condutas em cada setor). }\end{array}$} \\
\hline \multirow[b]{2}{*}{ Resultados } & Gerencialista & $\begin{array}{lr}\text { Aumento } & \text { na } \\
\text { arrecadação de } & \text { FGTS, } \\
\text { demandando } & \text { porém } \\
\text { envolvimento } & \text { de } \\
\text { quase todos fiscais. }\end{array}$ & $\begin{array}{l}\text { Impactos negligenciáveis } \\
\text { na mudança de práticas de } \\
\text { contratação. Dificuldades } \\
\text { na investigação. }\end{array}$ & $\begin{array}{lr}\text { Alto número de } \\
\text { autuações r com } \\
\text { pequena redução } \\
\text { do } r \text { risco } \\
\text { vivenciado r por } \\
\text { trabalhadores. }\end{array}$ \\
\hline & Experimentalista & 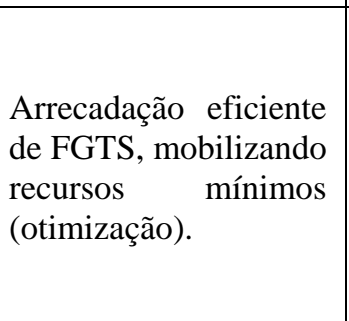 & $\begin{array}{l}\text { Mudanças nas práticas de } \\
\text { contratação em setores. } \\
\text { Investigações detalhadas / } \\
\text { evidências legais sólidas. } \\
\text { Efeitos demonstração. }\end{array}$ & $\begin{array}{l}\text { Desenvolvimento } \\
\text { de soluções } \\
\text { gerenciais e } \\
\text { tecnológicas, } \\
\text { ligando segurança } \\
\text { do trabalho com } \\
\text { qualidade/custo de } \\
\text { producão. }\end{array}$ \\
\hline
\end{tabular}

A partir do Quadro 1, é possível tirarmos três conclusões. Primeiro, cada modelo de gestão oferece sua própria estratégia por meio da qual supervisores controlam o trabalho de seus funcionários na linha de frente. Como indicado na descrição dos casos, as diferentes formas pelas quais superiores monitoram o desempenho de seus subordinados afetam a motivação e o desempenho dos últimos na realização de seus trabalhos. Após mais de duas décadas, até mesmo os analistas simpatizantes já reconheceram que reformas inspiradas na abordagem gerencialista falham em realizar a expectativa de uma administração pública mais eficiente e eficaz. Talvez, como afirmam alguns críticos, tais reformas tenham “expirado sua validade” à medida que não têm mais sido capazes de sustentar a energia que 
moveu seus primeiros passos (HOOD e PETERS, 2004; DUNLEAVY et al, 2006). Um volume considerável de críticas ao modelo já chamou atenção para os efeitos paradóxicos e disfuncionais de medidas de desempenho quantitativas e predefinidas (BOUCKAERT e BALK, 1991). ${ }^{16}$ Minhas entrevistas e observações confirmaram essas conclusões da literatura, uma vez que diversos auditores-fiscais reclamaram da introdução de indicadores quantitativos de desempenho por superiores, alegando a interferência dessas medidas na sua autonomia profissional, prejudicando tanto o seu comprometimento quanto o seu desempenho. A predefinição de metas específicas por gestores distantes da realidade da fiscalização do trabalho em campo favorece a prescrição de inspeções mecanizadas e burocráticas (seguindo um check list), pois os indicadores oficiais, de fato, determinam $a$ priori o que os fiscais deveriam considerar relevante ou o que deveriam ignorar, deixando de lado outros cursos de ação potencialmente mais efetivos na solução de um problema. Alguns fiscais repetidamente declararam sua frustração em não poder desenvolver alguns casos em maior complexidade (em períodos de tempo maiores e em parceria com outros agentes interessados no problema), tendo que seguir adiante para o próximo caso mesmo não alcançando mudanças significativas na atuação de empresas e nas condições de trabalho.

Em contraposição, os auditores-fiscais trabalhando sob o regime de equipes ou grupos especiais enfatizaram sua habilidade de desenvolver uma compreensão mais contextualizada e sensível a características setoriais importantes das violações, dos problemas no cumprimento da lei por parte das empresas e das próprias normas e legislação pertinentes. Tal como afirmou um auditor-fiscal do trabalho, "as atividades de inspeção se tornam menos focadas em como impor a lei e mais focadas em como estimular empregadores e trabalhadores a melhorar continuamente seus ambientes de trabalho”. Além disso, os casos estudados indicaram que equipes e grupos especiais estabelecem relacionamentos diferentes com os centros administrativos. Ao invés de meramente relatar resultados positivos ou insucesso na consecução das metas numéricas predeterminadas, a

\footnotetext{
${ }^{16}$ Pesquisas sobre médicos na Inglaterra e Estados Unidos revelaram que esses profissionais se sentem mais pressionados e menos motivados quando monitorados em termos de indicadores quantitativos de desempenho, além de desenvolverem práticas de "maquiagem” de números quando no preenchimento de relatórios (comunicação oral de E. McDonald e L. Miller, com o título "Tensions between Managerialism and Autonomy” no encontro anual da SASE - Society for the Advancement of Socio-Economics - em San Jose, Costa Rica, 23 julho 23 de 2008).
} 
esses grupos era concedida a liberdade para discutir a redefinição de metas, assim como de procedimentos e estratégias de fiscalização, à medida que desenvolvem suas operações. Além de submeterem-se a supervisão de gestores do nível central e estadual, o trabalho desenvolvido pelos grupos especiais também é submetido a outros mecanismos de controle: a pressão interna por parte da corporação e externa por parte dos parceiros que, uma vez engajados em ações conjuntas, constroem expectativas positivas a respeito do desempenho dos fiscais em cada operação. Esses elementos já foram também identificados em outros estudos como fontes importantes de motivação e desempenho de funcionários do serviço público, ainda que operando sob as condições mais adversas (TENDLER, 1997; JUSTICE 1986).

Segundo, as estratégias, rotinas e procedimentos adotados pelos fiscais sob cada um dos modelos influenciam de forma importante o padrão de intervenção e os resultados obtidos em cada caso. Como indicado pelos casos descritos na seção anterior, fiscalizações não planejadas, motivadas por denúncias e organizadas pelo sistema de zoneamento geográfico empregavam procedimentos de investigação não uniformes para empresas do mesmo setor e frequentemente falhavam na produção das evidências documentais necessárias para comprovar violações de direitos trabalhistas (tal como no caso das cooperativas fraudulentas). Mesmo que o sistema de gratificação por desempenho tenha levado a melhora nos resultados em um dos casos (arrecadação de FGTS), de forma geral, o processo de definição de metas quantificáveis, das medidas para atestar sua consecução e das recompensas para aqueles que as alcancem falha na redução da informalidade, das cooperativas fraudulentas e dos acidentes ocupacionais. Críticos da abordagem gerencialista sugerem que a definição de metas de desempenho específico e quantificáveis, em um contexto em que a implementação de políticas públicas é necessariamente fragmentada em diversos órgãos, reduz o escopo de ação e desincentiva burocracias a abordar problemas complexos e multidimensionais. ${ }^{17}$

\footnotetext{
${ }^{17}$ Essas reações críticas à abordagem gerencialista vêm não apenas de acadêmicos, mas também dos próprios funcionários e profissionais do serviço público. Em parte, essa crítica diz respeito à tendência observada em reformas gerencialistas de desagregar funções centrais (core) de outras funções consideradas auxiliares ou complementares, e especificar objetivos programáticos e tarefas organizacionais ao ponto de poder escrevê-las em um contrato. Tal como afirmam os críticos, essa tendência gera dificuldades para burocracias quando o problema é complexo, inter-relacionado, ou multifacetado, tais como saúde preventiva, reformas escolares, serviços de assistência à criança e ao adolescente, entre outros. Todos esses problemas ou objetos de políticas públicas requerem a coordenação de conhecimentos locais com uma gama de serviços produzidos por diferentes órgãos governamentais.
} 
Em oposição, a organização do trabalho de inspeção por meio de equipes e grupos especiais elimina alguns dos obstáculos para o desenvolvimento de operações que abordem setores como um todo e favorece interações contínuas entre os fiscais e diversos parceiros relevantes. Operações em nível de setor ou atividade econômica demandam diagnósticos sobre as causas do não cumprimento da lei, isto é, uma compreensão contextualizada das violações que permita a customização das ações de fiscalização para cada situação. Tal como articulado por diversos auditores-fiscais, eles deixam de pensar em como pegar mais e mais infratores, à medida que ganham maior autonomia para pensar por que empresas violam a lei.

Além disso, equipes de fiscalização que se orientam para setores (e não empresas individuais) incentivam fiscais a abordar problemas mais complexos e a praticar interdependência relacional em processos exploratórios juntamente com parceiros. Tal como demonstrado pelos casos apresentados anteriormente, grupo e equipes são mais propensos a buscar colaborações dentro e fora de sua organização, pois reconhecem que isoladamente suas ações não são suficientes para lidar efetivamente com problemas complexos. Além disso, as evidências apresentadas também sugerem que tais colaborações frequentemente levam a alguma combinação de soluções legais, gerenciais e tecnológicas para obstáculos ao cumprimento da lei (tais como a adaptação do DR aos canteiros de obras para mitigar acidentes fatais envolvendo choque elétrico).

Essas "conversas exploratórias" (PIORE, 2009; LESTER e PIORE, 2006) entre fiscais e outros atores governamentais e não governamentais são a fonte das inovações que permitem mudanças de práticas e o cumprimento da lei em setores tão diversos como os de saúde, tecnologia de informação e construção civil. Portanto, em contraposição à especificação "técnica" de metas e resultados e à imitação de incentivos para o desempenho utilizados em instituições de mercado, a abordagem experimentalista enfatiza a “administração deliberativa”. Isto é, a valorização de elementos como diálogo, negociação, acordos sequenciais e colaborações entre diferentes unidades da administração estatal e parceiros externos como elementos-chave da promoção de soluções criativas para problemas complexos (FISCHER e FORESTER, 1993; EVANS, 2005; BRUGUÉ, 2004; BACCARO e PAPADAKIS, 2009). Finalmente, as comparações entre os casos sugerem que a indução de melhor desempenho pode estar mais associada à valorização da 
autonomia de burocratas para inovar e aprender a partir da reflexão sobre suas próprias práticas (justificação) do que à criação de incentivos formais e pressões por maior produtividade em um conjunto restrito de resultados desejados. ${ }^{18}$

A terceira e última conclusão que podemos tirar do Quadro 1 sugere cautela em relação aos benefícios do modelo experimentalista na solução de problemas complexos. Sendo que o planejamento e execução de operações focadas em setores e as respectivas interações com parceiros estratégicos leva tempo até produzir resultados concretos, o trabalho de equipes e grupos especiais tende a se tornar menos responsivo às demandas imediatas de trabalhadores, assim como de representantes políticos e formuladores de políticas públicas. Mesmo que no médio a longo prazo as operações de grupos especiais sejam mais propensas a solucionar problemas relevantes e complexos, no curto prazo, situações perigosas ou ilegais vivenciadas por trabalhadores podem permanecer despercebidas e desatendidas (SILBEY, 1980; 1981). Em contraposição, sob o sistema de zoneamento, os fiscais têm maior liberdade de responder de imediato às denúncias de trabalhadores, mesmo que tais intervenções não venham a promover mudanças de longo prazo na atuação de empresas ou a afetar as causas do não cumprimento da lei. Para burocracias do setor público, tal como a fiscalização do trabalho, a responsividade é um atributo importante para a construção de uma boa reputação e imagem pública, assim como para a aglutinação de apoio político. Portanto, a possibilidade de combinação de ambos os métodos de gerenciamento da discricionariedade burocrática sob a mesma organização parece ser alternativa promissora no sentido de articular capacidade de resolução de problemas com responsividade, promovendo um equilíbrio desejado entre aquilo que March (1991) descreveu como as

\footnotetext{
${ }^{18}$ Inúmeros casos já demonstraram que a gestão do desempenho por meio da definição de metas específicas e da mensuração de sua consecução frequentemente leva burocratas a "maquiar" aquilo que eles podem ou sabem fazer de forma que pareça com aquilo que gestores especificaram como o resultado desejado. Um exemplo recente no New York Times apontou como um programa da autoridade imigratória norte-americana especificamente projetado para focar apenas em imigrantes com ordem de deportação já expedidas ou suspeitos de crime e terrorismo terminou por prender uma vasta maioria de imigrantes ilegais sem antecedentes criminais ou sem ordens de deportação. Em busca de "bater" cotas de detenção e demonstrar desempenho aos supervisores do programa, os funcionários da imigração começaram a "atirar” nos alvos mais fáceis (BERNSTEIN, 2009).
} 
funções organizacionais de exploração de novas possibilidades (exploration) e exploração de antigas certezas (exploitation). ${ }^{19}$

\section{Considerações finais}

Este estudo buscou examinar burocracias e seus modelos de gestão como um conjunto de instituições que prescrevem estruturas organizacionais, rotinas de operação e formas de interação entre atores, tais como burocratas, gestores e cidadãos. Com o intuito de explorar alternativas para o dilema entre controle da atuação burocrática e ampliação de sua capacidade de ação, a análise comparativa aqui desenvolvida indicou variações importantes nas estratégias adotadas por gestores para controlar a discricionariedade e o desempenho de funcionários de linha de frente. Tais variações indicam que análises aprofundadas de modelos de gestão, e como suas respectivas estruturas e procedimentos afetam o trabalho rotineiro de burocratas, podem de fato contribuir para uma nova compreensão a respeito do problema da discricionariedade em burocracias. Como vimos anteriormente, as variações entre modelos de gestão têm implicações importantes para a explicação de por que burocratas se comportam em algumas situações de forma mais conducentes ao aprendizado e à inovação. Os casos analisados indicam que certas características de modelos de gestão e as formas pelas quais estes organizam o trabalho na linha de frente - tais como a predefinição de metas de desempenho versus processos exploratórios (open-ended) com revisão constante dos objetivos, medidas de desempenho e procedimentos de fiscalização; trabalho individual versus em equipe etc. - afetam o grau no qual fiscais atribuem relevância e buscam oportunidades de trabalhar em parceria dentro e fora da organização no desenvolvimento de soluções efetivas para os obstáculos ao cumprimento da lei.

O material empírico apresentado também oferece suporte ao argumento de que a indução de melhora no desempenho de burocratas não envolve somente a definição de um sistema de incentivos (pecuniários) correto, mas, sobretudo, deve enfatizar: a) a construção de processos e dinâmicas para a revisão constante de objetivos organizacionais e das formas

\footnotetext{
${ }^{19}$ Obviamente, a questão passa a ser quanto espaço ou recursos alocar para cada modelo no âmbito de uma mesma organização. No caso da inspeção do trabalho no Brasil, atualmente é possível observar um deslocamento gradual para uma maior ênfase na organização da inspeção por meio de equipes e projetos especiais, deixando para trás a predominância do sistema de gratificação por desempenho. Fiscalizações responsivas e geograficamente circunscritas deverão permanecer, porém apenas como uma categoria residual, suficientemente para cobrir denúncias emergenciais feitas por trabalhadores em situações de grave vulnerabilidade (por exemplo, atraso ou não-pagamento de salários, risco eminente de morte ou acidente etc.).
} 
para sua mensuração; e b) a redefinição de mecanismos e procedimentos para a reformulação de rotinas de trabalho toda vez em que estas se tornarem hostis à consecução dos objetivos desejados. Portanto, uma compreensão mais profunda de como modelos de gestão evoluem em burocracias e como funcionários incorporam tais práticas nas suas rotinas de trabalho deveria ser aspecto indispensável da busca pela explicação do comportamento burocrático e seus impactos.

\section{Referências}

AMSDEN, A. A theory of government intervention in late industrialization. In: PUTTERMAN, L.; RUESCHEMEYER, D. (Orgs.) State and market in development: synergy and rivalry. Boulder: Lynne Riemer, 1992. p. 53-84.

BACCARO, L.; PAPADAKIS, K. The downside of deliberative public administration. Socio-Economic Review, v. 7, n. 2, p. 245-276, 2009.

BARDACH, E. The implementation game. Cambridge: MIT Press, 1977.

BARZELAY, M. The new public management: improving research and policy dialogue. California: University of California Press, 2001.

BAUMGARTNER, M. F. The myth of discretion. In: HAWKINS, K. (Org.) The uses of discretion. Oxford: Oxford University Press, 1992.

BERNSTEIN, N. Target of immigrant raids shifted. The New York Times, New York, US Section, 03.02.2009.

BITTNER, E. The police on skid row: a study of peace keeping. American Sociological Review, v. 32, n. 5, p. 699-715, 1967.

BITTNER, E. Aspects of police work. Boston: Northeastern University Press, 1990.

BOUCKAET, G.; BALK, W. Public productivity measurement: diseases and cures. Public Productivity \& Management Review, v. 15, n. 2, p. 229-235, 1991.

BRESSER-PEREIRA, L. C.; SPINK, P. Reforming the state: managerial public administration in Latin America. Boulder: Lynne Rienner, 1999.

BROWN, M. Working the streets: police discretion and the dilemas of reform. New York: Sage, 1981. 
BRUGUÉ, Q. Modernizar la administración desde la izquierda: burocracia, nueva gestión pública y administración deliberativa. Revista del CLAD Reforma y Democracia, v. 29, jun. 2004.

BRYNER, G. Bureaucratic discretion: law and policy in federal regulatory agencies. New York: Pergamon Press, 1987.

CALVERT, R.; MCCUBBINS, M.; WEINGAST, B. A theory of political control and agency discretion. American Journal of Political Science, v. 33, n. 3, p. 588-611, 1989.

CROZIER, M. The bureaucratic phenomenon. Chicago: The University of Chicago Press, 1964.

DAVIS, K. C. Discretionary justice. Baton Rouge: Louisiana State University Press, 1969.

DONER, R.; RITCHIE, B.; SLATER, D. Systemic vulnerability and the origins of developmental states: northeast and southeast Asia in comparative perspective. International Organization, v. 59, n. 2, p. 327-361, 2005.

DORF, M.; SABEL, C. A constitution of democratic experimentalism. Columbia Law Review, v. 98, n. 2, p. 267-473, 1998.

DUNLEAVY, P.; HOOD, C. From old public administration to new public management. Public Money and Management, v. 14, n. 3, p. 9-16, 1994.

DUNLEAVY, P.; MARGETTS, H. New public management is dead: long live digital-era governance. Journal of Public Administration Research and Theory, v. 16, n. 3, p. 467-494, 2006.

EVANS, P. Embedded autonomy: states \& industrial transformation. Princeton: Princeton University Press, 1995.

EVANS, P. Harnessing the state: rebalancing strategies for monitoring and motivation. In: LANGE, M.; RUESCHEMEYER, D. (Orgs.) States and development: historical antecedents of stagnation and advance. London: Palgrave, 2005. p. 26-47

EVANS, P. Predatory, developmental, and other apparatuses: a comparative political economy perspective on the third world state. Sociological Forum, v. 4, n. 4, p. 561-587, 1989. 
EVANS, P.; RAUCH, J. Bureaucracy and growth: a cross-national analysis of the effects of Weberian state structures on economic growth. American Sociological Review, v. 64, n. 5, p. 748-765, 1999.

FISCHER, F.; FORESTER, J. (Orgs.) The argumentative turn in policy analysis and planning. Durham, NC: Duke University Press, 1993.

GIBSON, J.; CALDEIRA, G.; SPENCE, L. The role of theory in experimental design: experiments without randomization. Political Analysis, v. 10, n. 4, p. 362-375, 2002.

GOULDNER, A. Patterns of industrial bureaucracy: a case study of modern factory administration. The Free Press, 1954.

GRIBBONS, B.; HERMAN, J. True and quasi-experimental designs: practical assessment. Research \& Evaluation, v. 5, n. 14, 1997. Disponível em:

http://PAREonline.net/getvn.asp?v=5\&n=14. Acesso em: 16.03.2009

HANDLER, J. Conditions of discretion: autonomy, community, and bureaucracy. New York: Sage, 1986.

HAWKINS, K. (Org.) The uses of discretion. Oxford: Oxford University Press, 1992.

HOOD, C.; PETERS, G. The middle aging of new public management: into the age of paradox? Journal of Public Administration Research and Theory, v. 14, n. 3, p. 267-282, 2004.

JOHNSON, C. MITI and the Japanese miracle: the growth of industrial policy, 1925-1975. Stanford: Stanford University Press, 1982.

JUSTICE, J. Policies, plans \& people: culture and health development in Nepal. Berkeley: University of California Press, 1986. p. 101-106,

LANGE, M.; REUSCHEMEYER, D. (Orgs.) States and development: historical antecedents of stagnation and advance. New York: Palgrave Macmillan, 2005.

LEONARD, D. K. Reaching the peasant farmer: organization theory and practice in Kenya. Chicago: University of Chicago Press, 1977.

LESTER, R.; PIORE, M. Innovation: the missing dimension. Cambridge: MIT Press, 2006. 
LIPSKY, M. Street level bureaucracy: dilemmas of the individual in public services. New York: Russell Sage Foundation, 1980.

MAYNARD-MOODY, S.; MUSHENO, M. Cops, teachers, counselors: stories from the front lines of public service. Ann Arbor: The University of Michigan Press, 2003.

MARCH, J. Exploration and exploitation in organizational learning. Organization Science, v. 2, n. 1, p. 71-87, 1991.

MCCUBBINS, M.; SCHWARTZ, T. Congressional oversight overlooked: police patrol versus fire alarms. American Journal of Political Science, v. 28, n. 1, p. 165-179, 1984.

MCCUBBINS, M.; NOLL, R.; WEINGAST, B. Administrative procedures as instruments of political control. Journal of Law, Economics, and Organization, v. 3, n. 2, p. 243-277, 1987.

MCDERMOTT, R. Experimental methodology in political science. Political Analysis, v. 10, n. 4, p. 325-342, 2002.

MILES, M.; HUBERMAN, M. Qualitative data analysis. London: Sage Publications, 1994.

MOMMSEN, W. J. The political and social theory of Max Weber: collected essays. Chicago, The University of Chicago Press. 1989.

NOONAN, K.; SABEL, C.; SIMON, W. The rule of law in the experimentalist welfare state: lessons from child welfare reform. Mimeo: Columbia Law School, 2007.

OSBORNE, D.; GAEBLER, T. Reinventing government: how the entrepreneurial spirit is transforming the public sector. Reading, MA: Addison-Wesley, 1992.

PIORE, M. Encontro anual da SASE (Society for the Advancement of Socio-Economics) 2008. San José, Costa Rica: Second thoughts: on economics, sociology, neoliberalism, Polanyi's double movement and intellectual vacuums. Socio-Economic Review, v. 7, n. 1, p. 161-175, 2009.

PIRES, R. Promoting sustainable compliance: styles of labour inspection and compliance outcomes in Brazil. International Labour Review, v. 147, n. 2-3, p. 199-229, 2008. 
POLLITT, C. Justification by works or by faith? Evaluating the new public management. Evaluation, v. 1, n. 2, p. 133-154, 1995.

PRESSMAN, J.; WILDAVSKY, A. Implementation. Berkeley: University of California Press, 1973.

SABEL, C. Beyond principal-agent governance: experimentalist organizations, learning and accountability. In: ENGELEN, E.; DHIAN HO, M. (Orgs.) De staat van de democratie. Democratie voorbij de staat. Amsterdam: Amsterdam University Press, 2004. p. 173-195.

SABEL, C. Globalisation, new public services, local democracy: what's the connection? In: Local Governance and the Drivers of Growth. Paris: OECD, 2005.

SABEL, C.; ZEITLIN, J. Learning from difference: the new architecture of experimentalist governance in the EU. European Law Journal, v. 14, n. 3, p. 271-327, 2008.

SILBEY, S. S. Case processing in an attorney general's office. Law \& Society Review, v. 15, n. 3-4, p. 849-881, 1981.

SILBEY, S. S.; BITTNER, E. The availability of law. Law and Policy Quarterly, v. 4, n. 4, p. 399-434, 1982.

SINDUSCON. Campanha de Prevenção de Acidentes do Trabalho na Indústria da Construção Civil no Estado de Pernambuco - Relatório 2005/2006. Sindicato da Indústria da Construção Civil no Estado de Pernambuco. Recife, 133, 2007.

TENDLER, J. Good government in the tropics. Baltimore: Johns Hopkins Press, 1997.

TROST, J. Statistically non-representative stratified sampling: a sampling technique for qualitative studies. Qualitative Sociology, v. 9, n. 1, p. 54-57, 1986.

VAN MAANEN, J. Observations on the making of policemen. Human Organization, v. 32, n. 4, p. 407-418, 1973.

VAN MAANEN, J. The asshole. In: MANNING, P.; VAN MAANEN, J. (Eds.) Policing a view from the street. 1978. p. 221-238.

WADE, R. Governing the market: economic theory and the role of government in Taiwan's industrialization. Princeton: Princeton University Press, 1990. 
WEBER, M. Essays in sociology. Tradução de H. H. Gerth e C. Wright Mills. Oxford: Oxford University Press, 1946.

WEBER, M. Economy and society. New York: Bedminster Press, 1968.

WILSON, J. Q. Bureaucracy: what government agencies do and why they do it. New York: Basic Books, 1989.

WILSON, J. Q. Varieties of police behavior: the management of law and order in eight communities. Cambridge: Harvard University Press, 1968.

Artigo recebido em 16/11/2009. Aprovado em 18/11/2009 